University of Chicago Law School

Chicago Unbound

Journal Articles

Faculty Scholarship

1989

\title{
Parliamentary Law, Majority Decisionmaking, and the Voting Paradox
}

Saul Levmore

Follow this and additional works at: https://chicagounbound.uchicago.edu/journal_articles

Part of the Law Commons

\section{Recommended Citation}

Saul Levmore, "Parliamentary Law, Majority Decisionmaking, and the Voting Paradox," 75 Virginia Law Review 971 (1989).

This Article is brought to you for free and open access by the Faculty Scholarship at Chicago Unbound. It has been accepted for inclusion in Journal Articles by an authorized administrator of Chicago Unbound. For more information, please contact unbound@law.uchicago.edu. 


\title{
PARLIAMENTARY LAW, MAJORITY DECISIONMAKING, AND THE VOTING PARADOX
}

\author{
Saul Levmore*
}

DARLIAMENTARY law is remarkably interesting for a number 1 of reasons. I do not mean that every citizen is fascinated by the question of whether under Robert's Rules of Order a motion to refer a matter to committee has priority over a motion to amend a main motion. (It does.) ${ }^{1}$ But both the general structure of deliberative assemblies' decisionmaking processes and many technical rules of order are quite interesting if examined from a perspective that recognizes the difficulty - and occasional impossibility-of divining the will of the inajority. Even apart from this link between parliamentary rules and the puzzles inherent in group decisionmaking, the evolution of voting rules is an interesting subject because it touches on two intriguing and interrelated phenomena: the evolution of law, and the

* Professor of Law, University of Virginia. I have benefited from the suggestions of Frank Easterbrook, Dan Farber, Richard Fallon, Daniel Ortiz, Richard Posner, Glen Robinson, Julie Roin, Roberta Romano, Robert Scott, and Barney Wilson, and from the participants at faculty workshops at the University of Chicago, McGill University, New York University, and the University of Virginia.

1 H. Robert, Robert's Rules of Order Newly Revised 50-51, 140-41 (1970). Under the rules of parliamentary procedure, if motion 1 has priority (or precedence) over motion 2 , then motion 1 can be made while motion 2 is before the assembly and can temporarily replace motion 2 as the immediately pending question. Motion 1 will be voted on before motion 2 . Moreover, motion 2 cannot be made while motion 1 is pending.

In the years since Henry Robert first published his rules of order in 1876, Robert's Rules has undergone two major revisions. Thus, there are three Robert's Rules of Order: the original Pocket Manual of Rules of Order for Deliberative Assemblies (1876) [hereinafter Pocket Manual], Robert's Rules of Order Revised (1915), and the current Robert's Rules of Order Newly Revised (1970). In this Article, unless otherwise specified, any reference to Robert's Rules is to Robert's Rules of Order Newly Revised (1970), which is the most accessible of the three versions.

In the years before the above revisions, minor changes were made with the release of each new edition. The changes in 1915 and 1970 were on a larger scale, involving major reorganization and expansion, but littlc, if any, change to the content of the previous version. There are, for example, no obvious contradictions between the current version and the original, despite the passage of more than one hundred years. More information about the different editions and versions is found in the preface to Robert's Rules of Order Newly Revised xxi-xxiv (1970). The rules discussed in this Article are by no means limited to Robert's Rules. See infra note 23 and accompanying text. 
occurrence of selective uniformity, or similarity, among different legal systems.

Part I of this Article contains sonie general observations on the development of voting procedures. The discussion in Part II develops the central argunient that there are hinks between collective choice problems, parliamentary rules of order, and general election procedures, ${ }^{2}$ and identifies an evolutionary mechanisn which may have forged these links. I argue that the nearly universal use of motions and amendments inside formal meetings can be readily explained and that "dissatisfaction" among coalitions on the losing end of the voting paradox generates certain kinds of changes in decisionnaking rules. Although this discussion can be seen as part of a larger conception about initation and innovation in law, ${ }^{3}$ the central role of collective choice theory in this Article suggests that the evolutionary story of parliamentary and other voting rules may be more exceptional than illustrative. Part III compares the rules used in deliberative assemblies such as legislatures, committees, clubs, and faculties, with those used in general elections and in many informal settings. ${ }^{4} \mathrm{I}$ try to refine the earlier argunients by explaining the differences between the rules used inside and outside formal neetings. Finally, the variety of procedures used in general elections is contrasted with the unifornity of the rules of order used in meetings.

2 By general election procedures, I refer to mechanisms used in general elections and in other settings outside of deliberative assemblies. Most of the comparisons between parliamentary rules and these "general" voting procedures are reserved for Part III.

3 See Levmore, Variety and Uniformity in the Treatment of the Good-Faith Purchaser, 16 J. Legal Stud. 43 (1987) [hereinafter Good-Faith Purchaser]; Levmore, Rethinking Comparative Law: Variety and Uniformity in Ancient and Modern Tort Law, 61 Tulane L. Rev. 235 (1986) [hereinafter Rethinking Comparative Law].

4 Plurality voting, also known as election by a relative majority, or the "first-past-the-post" system, is the most common method of electing public officials in the United States and England. See E. Lakeman, How Democracies Vote 29-35 (4th ed. 1974) ("The system most familiar to citizens of the United Kingdom is the election of one person at a time by a relative majority .... ); 5 Rokkan, Electoral System, International Encyclopedia of the Social Sciences 11-12 (1968) ("[O]ne round of election, with decision by simple plurality . . . became the standard method in the United States."). The use of plurality voting outside, but not inside, deliberative assemblies is the primary subject of Part III. 


\section{The Basic Structure of Parliamentary LaW}

\section{A. Historical Development}

The most provocative but frustrating questions about democratic processes are those concerning the developments of voting and majority rule itself. It is easy to imagine prehistoric circumstances in which some group agreed to be bound by a vote, but it is just as likely that decisionmaking within and among clans was purely hierarchical. Successful leaders must have been sensitive to their followers' opinions, and serious divisions often may have generated either compromises, permanent splits, or changes in leadership. None of these occurrences, however, really approaches the idea of democracy. There is simply no evidence of -and no logical reason why there must have been-very ancient votes.

The codification of laws, as opposed to the methods of their enactment, appears to predate the beginnings of democracy. The earliest (surviving) codes contain no reference to the conditions or context of their original passage or acceptance. ${ }^{5}$ And the Book of Exodus, which does describe the circumstances of the presentation and receipt of a set of laws, reports that these laws were accepted by the unanimous assent of an assembled group. ${ }^{6}$ Even if this report, and others like it, are exaggerations or inspirational creations, it is significant that later readers of Exodus were expected to recognize that unanimous assent by spiritual or physical ancestors somehow serves to bind later generations. The very fact that it is difficult to imagine a Biblical report that seventy-two percent of the Israelites voted for the Ten Commandments emphasizes that majority rule, and related procedures, is a much less powerful image and norm than other expressions of group solidarity. I do not mean to argue that substantive rule systems necessarily predated the evolution of democratic processes. For instance, it would not be shocking to discover that an early clan had the custom

5 Neither of the two oldest known codes, those of Eshnunna and Hammurabi, addresses the manner of its acceptance. Indeed, no reference to any kind of voting is made. See $1 \mathrm{G}$. Driver \& J. Miles, The Babylonian Laws (1952); R. Yaron, The Laws of Eshnunna (1969). See also $T$. Jacobsen, Toward the Image of Tammuz and Other Essays on Mesopotamian History and Culture $372 \mathrm{n} .12$ (1970) ("[T]he technique of reaching decisions by count of votes was not in use in Mesopotamia.").

${ }^{6}$ Exodus 24:3 ("Moses came and told the people all the words of the Lord and all the ordinances; and all the people answered with one voice and said, "All the words which the Lord has spoken we will do.'"). 
of following its leader unless two-thirds of the hunters "voted" otherwise, but that it had no continuing substantive rules, so that each theft or insult was treated by the clan or its leader as an isolated question. There is, however, simply no evidence of truly ancient voting procedures while there is evidence of ancient substantive rules regarding nearly every area of law other than voting. ${ }^{7}$

Two of the earliest references to voting procedures bear special mention because they touch on topics considered in some depth in this Article. In Aeschylus' Eumenides, Athena convenes a committee of ten or twelve Athenians to try Orestes in what is supposed to be the first homicide trial in history. ${ }^{8}$ Athena's deciding, or "casting," vote, revisited later in this Article, ${ }^{9}$ acquits the defendant in a setting where a simple majority would have decided the matter. The scene is plainly meant to signal the beginning of both democracy and the reign of law. ${ }^{10}$ The second instance of early voting is the conviction of Socrates by a 280-220 "jury" vote; Socrates was then sentenced to death by a more substantial majority of the 500 jurors. ${ }^{11}$ The episode makes the modern reader wonder, among other things, whether it was possi-

7 The Laws of Eshnunna, Hammurabi's Code, and the Book of Exodus all contain provisions relating to many different areas of law, such as tort, contract, property, and family law. See Levmore, Rethinking Comparative Law, supra note 3. Voting is not mentioned. Interestingly, in the surviving fragments of tablets of the Old Assyrian Laws, the word "majority" appears in the context of some sort of judicial panel. Unfortunately, the tablets are terribly fragmented and the information "which can be gleaned from them in their present state is all too meagre." G. Driver \& J. Miles, The Assyrian Laws 1-3, 376-77 (1937).

The earliest known lawgivers of ancient Athens were Draco, in 621 B.C., and Solon, in 594 B.C., who seems to have retracted most of Draco's harsher laws. R. Bonner, Aspects of Athenian Democracy 29-30 (1933). These lawgivers seemed to have been appointed or delegated, but there is no evidence or report of any voting on the adoption of the laws that were then drafted. But see E. Stavely, Greek and Roman Voting and Elections 25 (1972) (noting that "there is no good reason to reject the tradition that he [Solon] gave some recognition to a form of popular Assembly, which presumably began to express itself by means of a vote").

81 G. Thompson, The Oresteia of Aeschylus 54 (1966) ("Athena has returned, accompanied by her chosen judges, probably ten or tweive in number, who are followed by the citizens of Athens, eager to witness the first trial for homicide in the history of man . . . ").

9 See infra notes $115-18$ and accompanying text.

10 See G. Thompson, supra note 8 , at 55 (referring to the trial and noting that " $[t]$ he reign of law has begun. ... . The conflict between tribal custom and aristocratic privilege has been resolved in democracy.").

11 Based in part on the passage in Plato's Apology where Socrates says, "if only thirty votes had fallen otherwise, I would have been acquitted," it is often assumed that there were 500 jurors divided 280-220. R. Allen, Socrates and Legal Obligation 56, 135 n.24 (1980). However, there is other evidence that councils of 501 were used in criminal trials of the time. 
ble for an Athenian voter to abstain, how juries caine to their present size, and whether there is a relationship between jury size and the (now coininon) requireinent of unanimity or a substantial supermajority to convict a criminal defendant. ${ }^{12}$ There are several other ancient references to voting, and some are quite striking, ${ }^{13}$ but none is as detailed as the two just mentioned.

There are, unfortunately, few other clues about the existence or details of ancient or even medieval voting. Turning to the focal points of this Article, the historical origins of plurality voting, the inaking of motions, and generally accepted rules of order in (and outside of) deliberative assemblies are largely unknown. There is some evidence that a form of motion-and-amendment voting was used in Athens in the fourth century, but the details of such voting procedures are

See R. Bonner, Lawyers and Litigants in Ancient Athens 36, 255 (1927) (describing Socrates' trial as involving 501 jurors who convicted the defendant by a majority of 61 ).

12 There is, I believe, too much danger of corruption in a very large jury if unanimity is required. A requirement of unanimity in very large groups, therefore, would be unexpected. See infra text following note 112. The recurring appearance of secret ballots in ancient times, see, e.g., E. Stavely, supra note 7, at 84, 96-99; Larsen, infra note 13, at 170, is, I think, necessarily correlated with the number of voters. With a large number of voters and a simple majority requirement, corruption is unlikely to be a major problem. A small group of jurors, however, operating under a unanimity requirement must fear investigation-that is, must not vote secretly - or they may be too easily corrupted.

Note that as a probabilistic matter, a simple majority of a very large number of voters may be said to be correct at least as much as a supermajority of a smaller group. See Kuflik, Majority Rule Procedure, in Due Process: Nomos XVIII 305-06 (J. Pennock \& J. Chapman eds. 1977).

13 The best discussion I have found is Larsen, The Origin and Signiflcance of the Counting of Votes, 44 Classical Philology 164 (1949). The few instances discussed in this source that involve choices among more than two alternatives all appear to have been resolved by simple plurality. The best example, see id. at 168-69, concerns the Spartan practice of filling a vacancy in the council of elders by having candidates pass in random order before the assembly and having judges, who were sequestered in a building out of sight of this assembly, determine which candidate was greeted by the "most and the loudest shouting."

This Spartan practice is an especially rich precedent because although it seems to have been a primitive form of plurality voting, this is only so if each member cheers only for his favorite candidate. If, however, members reasoned that the best strategy included cheering for all acceptable candidates, in order to minimize the relative noise associated with the unacceptable candidates, then Sparta practiced an early form of "approval voting," see infra note 162 . And if the assembled members roared loudest for their favorites, loudly for their second preferences, and so forth, so that intensity of preferences was measured, the practice should be understood as an early form of "preference voting," see infra note 121. Larsen regards the practice of taking formal votes as dating from the seventh century B.C. See also R. Posner, The Economics of Justice 128-29 (1981) (commenting on early decisionmaking and noting one Homeric example of a minority simply declining to follow a majority's plan). 
unknown. ${ }^{14}$ Leaping across many centuries, early entries in the Journal of the House of Commons illustrate the presence of rules in the late sixteenth and early seventeenth centuries, such as "a Rule, That the Chair-man shall ask the Parties that would speak, on which side they would speak . . . and the Party that speaketh agamst the last Speaker, is to be heard first." 15 But there is no reason to think that these rules sprang from the mind of some member of Parliament in the sixteenth century, much as there is every reason to believe that most common law rules have origins predating early English courts. It is more likely that similar practices-some critical, some trivialevolved in various corners of the globe. My guess is that rules in this group include following a preannounced agenda, requiring a vote to adjourn, and barring the easy reconsideration of decisions. Other rules currently in use may indeed have been the product of sudden innovation in the English Parliament. This latter category may include rules confining debate to the merits of the pending question, requiring a "second" before voting on a proposal, and calling on the convener to suppress discussion that contains interpersonal attacks or "reviling or nipping words." 16 But I mean only to suggest the likelihood that some procedural rules are the products of a long evolution while others originated only after parliaments and clubs as we know them began to meet, and not that certain rules necessarily fall into one group or the other.

The evolution of parliamentary law in the United States is in one sense easy to trace and in another quite intriguing. In purely chronological terms, there was a transatlantic migration of English rules, ${ }^{17}$ alteration of those rules in the colonial legislatures, ${ }^{18}$ the emergence of

14 See M. Hansen, The Athenian Ecclesia 120-21 (1983) (In electing board of ten, if first candidate put forward was accepted, then a new candidate could be named in which case people made a choice between the two by a show of hands, after which another could be proposed, and so forth.).

$15 \mathrm{H}$. Robert, supra note 1, at xxxi. Robert notes several other early rules (with the dates of their original appearance in the Journal of the House of Commons) that are still used in assemblies today. Among those listed are entertaining only one subject at a time (1581), requiring the chair to always call for the negative vote (1604), avoiding references to personalities during debate (1604), and dividing multipart questions (1640).

16 Id.

17 See id. at xxxii; Carmack, Evolution in Parliamentary Procedure in Readings in Parliamentary Procedure 21 (H. Bosmajian ed. 1968).

18 See H. Robert, supra note 1, at xxxii ("The manner in which these rules and customs were adapted to meet the situation within each colony may account for the local variance in 
Thomas Jefferson's Manual of Parliamentary Practice-modeled on English Parliamentary practices and adopted in the United States Senate (where Jefferson presided), in various state legislatures, and initially in the House of Representatives until the House developed its own rules and practices ${ }^{19}$-and finally the 1845 publication of Luther Cushing's Manual of Parliamentary Practice, ${ }^{20}$ containing rules intended for both legislative and private assemblies. In the years following the Civil War, a large number of innovators, imitators, and educators published rules of order, plainly designed for the expanding market of citizens attending town meetings, volunteer organization functions, and political action sessions (for such causes as universal suffrage). ${ }^{21}$ Many of these parliamentary guides contain reference charts which could be consulted in the heat of debate and many were published in sizes that could fit into purses. Henry Robert, whose job as an Army Engineer caused him to travel throughout the nation, authored one of these guides after experiencing the confusion engendered by the lack of uniformity among the various regional customs. ${ }^{22}$

parliamentary tradition which persisted among people in this country long after the founding of the United States, and which would eventually be one of the conditions that led to the writing of Robert's Rules of Order."); see also Carmack, supra note 17.

19 See H. Robert, supra note 1, at xxxiv (In writing his manual, Jefferson "extensively cited about fifty English" sources and acknowledged "primary indebtedness to Precedents of Proceedings in the House of Commons by John Hatsell."); see also Carmack, supra note 17, at 27 ("This British practice of ordered change which respects tradition, precedent, and court decisions was transplanted from the 'Mother Country' to America in the workings of colonial legislation and meetings, but it was Thomas Jefferson who made the transfer official" with the publication of his manual.).

20 See Carmack, supra note 17, at 31 ("Cushing wrote from a lawyer's viewpoint observing correct legal forms of parliamentary procedure, based on the decisions of the courts of previous years." His Manual "is the direct predecessor of Robert's Rules of Order. It is the only book to rival Robert's in amount of sales and dominance of the field by universal usage."); see also Doyle, Rules of Order: Henry Martyn Robert and the Popularization of American Parliamentary Law, 32 Am. Quarterly 3, 5 (1980) (Cushing's Manual differed from those to follow because it meant to lay down basic principles "that would inform the leaders of voluntary societies as they designed their own procedural rules." Robert and his contemporaries wrote sets of rules which were intended to be adopted as the procedural rules of an organization.).

21 See Doyle, supra note 20, at 6 ("By the turn of the century the national integration of markets, professional societies, reform movements, and a wide variety of interest groups accelerated into what historians have described as an "organizational revolution." ").

22 That there were many different people and types of people writing rules of order is made clear by Doyle as he describes Robert's frustration while in San Francisco from 1867-1871:

Those in San Francisco who did have familiarity with parliamentary procedure ran head-on into the disparity of practices among the different states. State and regional 
The fact that (successor editions of) Robert's Rules of Order eventually emerged as the preeminent code of parliamentary law should not mask the point that it was but one of many competitors, each of which borrowed from and modified previous practices and publications. $^{23}$

customs that might have coexisted with little friction in the East grated harshly within the meeting halls of San Francisco, where no previous tradition held sway and no single stream of immigration could impose its own parliamentary customs. "San Francisco was made up of people from every state in the union," Robert recalled, "and consequently members were being constantly ruled out of order, and there was no way to determine what was in order as the presiding officer followed the customs of the section from which he came." "I had resided in eleven different states, but it was my San Francisco experience that showed me the importance of having some Rules of Order adapted to deliberative assemblies, other than legislative, that might be adopted by societies in various parts of the country, and avoid the unprofitable disputes as to what were the rules of parliamentary law."

Id. at 11 .

23 The success of Robert's Rules seems to have had more to do with Henry Robert's initial decision to promote his work by supplying organizations with copies at his own expense, see H. Robert, supra note 1 , at xli, and with the continuing interest Robert (and others) put in his project than with any particular innovations.

There are a surprising number of different sources of rules of order for deliberative bodies. In writing this Article I have consulted a large (but not complete) sample of published guides to parliamentary law in the United States. (J. O'Brien, infra, lists more than 100 sources of parliamentary law in his bibliography.) As will become clear, there is substantial similarity among these authorities so that generalizations about parliamentary law are often easily made. The authorities I consulted, in chronological order, are as follows: T. Jefferson, Jefferson's Manual of Parliamentary Practice (1801), reprinted in Rules of the House of Representatives, H.R. Doc. No. 279, 99th Cong., 2d Sess. (1987); L. Cushing, Manual of Parliamentary Practice (1845) [hereinafter Manual]; L. Cushing, Elements of the Law and Practice of Legislative Assemblies in the United States of America (1856) [hereinafter Law and Practice]; B. Mathias, Rules of Order: A Manual for Conducting Business in Town and Ward Meetings, Societies, Boards of Directors and Managers, and Other Deliberative Bodies (7th ed. 1855); P. Mell, Rules for Conducting Business in Deliberative Assemblies (1868); H. Robert, Robert's Rules of Order Newly Revised (1970) (updating earlier editions of Robert's, the first of which was in 1876, see supra note 1); R. Waples, A Handbook on Parliamentary Practice (1883); U. Smith, Smith's Diagram of Parliamentary Rules (2d ed.1886); F. Kerfoot, Parliamentary Law (1897); T. Reed, Reed's Rules: A Manual of General Parliamentary Law (1897); H. Shattuck, The Woman's Manual of Parliamentary Law (6th ed. 1897); E. Palmer, A New Parliamentary Manual (1901); W. Henry, How to Organize and Conduct a Meeting (rev. ed. 1902); J. Robert, Robert's Primer of Parliamentary Law (1908) (by Henry Robert's brother); F. Gregg, Handbook of Parliamentary Law (1910); N. Paul, Parliamentary Law with Forms and Diagram of Motion (1910); C. Gaines, The New Cushing's Manual of Parliamentary Law and Practice (1912); M. Plummer, Practical Lessons in Parliamentary Procedure (1924) (based on Robert's Rules); E. McKelvey, Ritual of Parliamentary Law for Ordinary Assemblies Revised (1934) (a lesson book in accord with Robert's Rules); J. Auer, Essentials of Parliamentary Procedure (2d ed. 1942); Z. Moore \& J. Moore, Essential of Parliamentary Procedure (1944); R. Cruzan, Practical Parliamentary Procedure (1947); O. Jones, Parliamentary Procedure at a 
Alongside the emergence of various codes or guides to parliamentary procedure, there were obviously many other developments and evolutionary forces that contributed to the form and substance of modern democracy. The evolution of national boundaries, internal jurisdictions, and the relationships between the two is perhaps the most obvious set of examples of such influences. The impact of a given voter's preferences on group decisionmaking plainly depends on jurisdictional boundaries in existence when the preferences are recorded. Another, less global, development affecting democratic outcomes is the electoral process when there are multiple candidates. Although the precise birth of majority and plurality voting is unrecorded, it is easier to trace the subsequent emergence of plurality voting with a runoff (or double ballot voting), "single transferable" and other preference voting systems, and various forms of proportional representation. ${ }^{24}$ The coexistence of these several "election types" in contemporary democracies, in both the public and private spheres, is a convenient modern example of variety where reasonable people could disagree about the relative desirability of different rules. ${ }^{25}$

Although this Article's central focus is on what has become known as "parliamentary law," or the rules of order followed at relatively formal meetings, I will continue to draw special attention to the development of election types, and especially plurality voting, in democratic decisionmaking in order to note and eventually explain a striking contrast. In many ways the election of representatives is similar to decisionmaking within a deliberative assembly. In both situa-

Glance (1947); J. Tilson, A Manual of Parliamentary Procedure (1949); A. Sturgis, Sturgis Standard Code of Parliamentary Procedure (1950); J. O'Brien, Parliamentary Law for the Layman (1952); J. Karcher, Handbook on Parliamentary Law (1952); P. Mason, Mason's Manual of Legislative Procedure (1953); L. Bridge, The Funk \& Wagnalls Book of Parliamentary Procedure (1954); H. Davidson, Handbook of Parliamentary Procedure (2d ed. 1968); G. Demeter's Manual of Parliamentary Law and Procedure (1969); W. Gondin, Dictionary Handbook of Parliamentary Procedure (1969); R. Keesey, Modern Parliamentary Procedure (1974); H. Oleck, Parliamentary Law for Nonprofit Organizations (1979).

${ }^{24}$ See, e.g., G. Hallett \& C. Hoag, Proportional Representation-The Key to Democracy 105-06 (1926) (discussing the development of proportional representation and the single transferable vote); D. Black, infra note 41 , at 156-88 (discussing the inception of preferential voting).

${ }_{25}$ See generally Levmore, Good-Faith Purchaser, supra note 3, at 43-44 ("Variety among legal systems often arises in rules that either (a) do not much matter or (b) raise issues about which reasonable people (even in the same culture) could disagree."). 
tions it may be convenient for there to be only two alternatives ${ }^{26}$-and in our legislatures, for example, the two major political parties often serve to limit choices, at least by the time of formal decisionmaking $^{27}$ — but there are often three or more alternatives to consider. Interestingly enough, while plurality voting is a rather common voting procedure for selecting a group leader or the members of an assembly, inside the assembly it is never used to reach decisions. Virtually all authorities on parliamentary law require that motions and amendments be voted up or down, one at a time, by majority or supermajority vote. ${ }^{28}$ The equivalent election procedure among three candidates for a congressional seat, for example, would require two candidates to compete head-on, with the survivor running in a second

26 The "will of the majority" is easiest to define and discern with only two alternatives. Quorum, tie-vote, and abstention questions aside, there will be an absolute majority for one of the proposals. It is when three or more alternatives are pending and none receives an absolute majority that interesting questions about the substance of majoritarianism arise. There is simply no collective-choice difficulty in the face of only two alternatives. See Kramer, Some Procedural Aspects of Majority Rule, in Due Process: Nomos XVIII, supra note 12, at 264, 265-66.

27 See W. Riker \& P. Ordeshook, An Introduction to Positive Political Theory 104 (1973). The authors point out that "the two party system in well-disciplined legislatures requires that there be at most two alternatives appearing first in any legislator's ordering." Thus, one of the two party-backed alternatives will achieve an absolute majority of the votes in the first round of voting.

Of course, even when the two parties discipline their members so that only two alternatives compete, there are often more than two alternatives previously considered within the party. A strong two-party system may therefore simply suppress evidence of intransitivity-a problem reviewed and discussed at length in Part II. Thus, the "ruling" party in a parliamentary system may put forth a budget proposal after debating four or five proposals within the party. The proposal may be subject to attack and amendment by the "opposition" party in parliament, but by virtue of the dominance of the two parties there is no opportunity for a member to seek backing from within the ranks of both parties for what might have been the second choice of the ruling party.

28 See, e.g., H. Robert, supra note 1 , at 3 ("The basic principle of decision in a deliberative assembly is that ... a proposition must be adopted by a majority vote."); A. Sturgis, supra note 23 , at 3-8 (two of the eleven basie principles underlying parliamentary law are "[t]he vote of the majority decides" and "[o]nly one question can be considered at a time").

The rules also make it difficult for a proposition which has been decided, either as a main motion or an amendment, to be considered again. See, e.g., H. Robert supra note 1, at 113 ("During the session in which the assembly has decided a question, another main motion raising the same or substantially the same question cannot be introduced."); id. at 111-12 ("Only one primary amendment and one secondary amendment are permitted at a time, but any number of each can be offered in succession-so long as they do not again raise questions already decided."). All the rules, however, contain a "motion to reconsider," whereby a member of the prevailing side on a decision by the assembly may ask for a vote on whether or 
ballot against the third candidate. ${ }^{29}$ It is obvious both that this is not the usual election procedure ${ }^{30}$ and that plurality and many other voting procedures, which are found frequently in primaries and general elections, are conspicuously absent inside legislatures and meeting halls. This contrast is explored at great length and is, I think, explained in Parts II and III, but initially it will be helpful to develop a more complete picture of the structure, constants, and variations in parliamentary law.

\section{B. Uniformity}

Regardless of whether the various authorities on parliamentary procedure are viewed as competing codifiers, evolutionary successors, or parallel operators, ${ }^{31}$ comparing these authorities is analagous to comparing legal systems in general. As such, a familiar strategy is to catalogue the similarities and dissimilarities, or the uniformity and variety, among rule systems and then to provide a coherent explanation of both. ${ }^{32}$ Indeed, as an abstract matter, comparative methods

not to reconsider that decision. A motion to reconsider requires only a majority vote regardless of the vote necessary to pass the motion being reconsidered. See, e.g., id. at 270 .

As for reconsidering failed amendments, the general rule is that the amendment can only be reconsidered if its "object" has not yet been voted on or if its object is under reconsideration. See, e.g., id. at 268 ("Reconsider can be applied to the vote on a secondary amendment only in such a way that the reconsideration takes place before the primary amendment involved is voted on or while the primary amendment is being reconsidered.").

29 In deliberative bodies if a motion (A) is proposed, followed by an amendment (B), and then a secondary amendment $(C)$, a decision is first made between $C$ and $B$, with the winner then competing against A. See, e.g., H. Robert, supra note 1 , at 120-22; infra note 39.

${ }^{30}$ This is simply not one of the very many procedures found in the world for electing candidates to public office. See generally E. Lakeman, supra note 4 (discussing the history, structure, and limitations of various electoral systems).

31 To the extent that the authorities were aware of one another's work and sought a share of the same market, it is obvious that they competed with one another and had incentives to develop "better" or better marketed rules. See, e.g., F. Gregg, supra note 23 (using small pictures to communicate the "laying down" of motions and other maneuvers with catchy analogues); U. Smith, supra note 23 (diagrams). To the extent these authorities came in waves, see supra note 23 , it is easy to imagine that innovation opened the market, and then different entrants sought to update earlier authorities. Finally, at least some of the authors saw themselves as filling particular niches, with rules "parallel" to those of other authorities. See, e.g., J. O'Brien, supra note 23 , at xix-xxi (stressing means of learning parliamentary rules and importance of such learning "as a weapon against communism and other un-American isms"); H. Oleck, supra note 23 (rules for nonprofit organizations); H. Shattuck, supra note 23 (a special manual for women).

32 See Levmore, Good-Faith Purchaser, supra note 3, at 43-44. I have previously stressed the role of "unusual" uniformity and variety in "uncompelled" fundamental rules. See 
are likely to be applied with unusual precision to parliamentary rule systems because many of the usual distractions in comparative law will be absent. More specifically, the rules of order found in one of the many American guides to parliamentary law are obviously not the result of conquest, and comparisons among the functional, moral, or other features of these rule systems are free from claims that legal rules and their underlying cultures are so intricately intertwined that it is pointless either to think about transposing rules or to explain them on their own merits.

A fair amount of uniformity is apparent in any survey of parliamentary law. All authorities prescribe or assume the election of a chairperson to call on members and rule on procedural questions, the power of the assembly to overrule the chair's decisions, the passage of most motions by a majority vote, the possibility of reconsidering previous actions, especially if one who voted for the earlier action favors such reconsideration, and many other unsurprising background rules. $^{33}$ At a more trivial level, the various authorities, or codes, attach the same labels to various procedural devices, such as inotions to put the question aside temporarily or "lay on the table," and to end debate and "call" or vote on the "previous question." 34 There is even remarkable agreement on the ranking of, or order of voting among, various procedural devices. Robert, in 1876, ranked the motions from highest to lowest as follows: adjouru, raise a question of privilege, lay on the table, previous question, postpone definitely, commit to com-

Levmore, Rethinking Comparative Law, supra note 3, at 237-40. My goals in this Article are quite distinct from these concepts and from earlier projects, although the arguments in this Article do ultimately support and extend my earlier claims about uniformity and variety in legal systems.

33 See, e.g., R. Cruzan, supra note 23, at 180 (election of the chair); id. at 52 (duties of the chair); id. at 131-34 (overruling the chair); id. at 44 (majority voting); id. at 78 (motion to reconsider); H. Davidson, supra note 23, at 56 (election of the chair); id. at 53 (duties of the chair); id. at 58 (overruling the chair); id. at 8 (majority voting); id. at 159-68 (motion to reconsider); $H$. Robert, supra note 1 , at 458 (election of the chair); id. at 376 (duties of the chair); id. at 218-22 (overruling the chair); id. at 3-4 (majority voting); id. at 265-84 (motion to reconsider).

By "background rules" I refer to structural or basic characteristics that might easily appear in different legal systems. For instance, the presence in all legal systems of penalties for murderers, however defined, is quite unsurprising.

34 See, e.g., R. Cruzan, supra note 23, at 118 (lay on the table); id. at 120 (previous question); H. Davidson, supra note 23, at 103 (lay on the table); id. at 69 (previous question); H. Robert, supra note 1, at 177-85 (lay on the table); id. at 166-76 (previous question). These appear simply to have been copied by the various parliamentary authorities. 
mittee, amend, postpone indefinitely, and, finally, main motion. ${ }^{35}$ Although some of the later parliamentary authorities added a few causes of action, so to speak, none changed the relative rank of more than one motion. ${ }^{36}$ There is, in short, remarkable uniformity about the procedural possibilities and their relative priority. Similarly, virtually all authorities prohibit tertiary amendments. ${ }^{37}$ Additional alternatives can be introduced, so the rule has limited substantive impact, but the mover of a fourth alternative must await the rejection of at least one of the questions before the assembly. More strikingly, perhaps, virtually all the guides call for a two-thirds vote, as opposed to some other supermajority, to suspend the assembly's rules of order. ${ }^{38}$

I have labored through these examples of uniformity, much of which is surely the product of simple imitation, to set in stark relief the occasional variety among parliamentary rule systems. The discus-

35 H. Robert, Pocket Manual, supra note 1, at 10, 23. Even prior to Robert's first effort, Mathias reported a similar ranking of motions in the Congress: adjourn, lay on the table, previous question and question of privilege (not ranked against one another), postpone indefinitely (unclear rank), commit, amend, and, finally, main motion. B. Mathias, supra note 23 , at $69-70$.

36 Among the authors who allow and clearly rank the motions listed below there is little variation from the following order: fix a time to adjourn, adjourn, recess, raise a question of privilege, lay on the table, previous question (close debate), postpone definitely, commit, amend, and postpone indefinitely. See, e.g., G. Demeter, supra note 23, at 10; Z. Moore \& J. Moore, supra note 23, at 46-47; J. O'Brien, supra note 23, at 19-21.

37 Of the sources listed in note 23 , only one disallows secondary amendments. R. Keesey, supra note 23 , at $43-44$. H. Robert, supra note 1 , at 111 , is more receptive and typical: "An amendment of the third degree is not permitted, since it would make the parliamentary situation too complicated." See also R. Cruzan, supra note 23, at 31 ("There can be only two [amendments] pending at one time, one of third degree is not permitted."). A few authorities, however, do permit voters to consider four or five alternatives at once, through the amendment process. See infra note 80; see also infra note 81 (discussing disadvantage of numerous pending alternatives).

38 See, e.g., F. Gregg, supra note 23 , at 27 ; H. Robert, supra note 1 , at 11 . The assembly's rnles of order govern the parliamentary procedure used in conducting business. These rules differ from, and in some sense stand in between, bylaws and standing rules. The bylaws (and constitution) of an organization contain the basic or more permanent provisions relating to the organization itself, such as the name of the association, its object, its officers, and its parliamentary authority, which is a particular manual adopted as the assembly's rules of order. The standing rnles relate to details of administration, such as the hours of the meetings, and are essentially previously adopted main motions. The standing rules are the least permanent, usually subject to change by a majority vote, whereas bylaws are the most permanent, usually requiring advanced notice of any vote on a proposed change and a supermajority to adopt the change. See, e.g., H. Robert, supra note 1, at 10-15. 
sion in Part II sketches and offers an explanation for some of this variety by describing an evolutionary enzyme in parliamentary law, and then returns to the striking uniformity of the "motion-andamendment" process inside, but not outside, deliberative assemblies. ${ }^{39}$

\section{Parliamentary Law and the Voting Paradox}

The remainder of this Article explores the intersection between procedural rules and the "impossibility" of "coherent" collective choice. The discussion assumes only passing acquaintance with the social choice literature and with commonly used rules of order, and I will make no attempt to review the vast literature on social choice in any depth or detail. I trust that readers who have studied this literature will find the argument more rather than less interesting, and will excuse the occasional explanations provided for the uninitiated. ${ }^{40}$

\section{A. Elements of Collective Choice Theory}

A large part of the argument in this Article concerns the "voting paradox," or the idea that collective decisions may lack coherence

39 It may be useful to describe this motion-and-amendment process for readers who have been (mercifully) spared the experience of regular attendance at formal meetings. Under parliamentary procedure, the principle way of bringing business before a group and of making decisions is with a motion. While the motion is "open to debate," but before it is voted on, a member may move, among other things, to amend the motion. This motion is called a primary amendment, or an amendment to the first degree. The immediate question now before the group is whether or not to amend the original motion. While this amendment is "pending," however, another member may move to amend the primary amendment. This motion is called a secondary amendment, or an amendment to the second degree. The secondary amendment always is voted on first, so there is essentially a choice between the secondary and the primary amendment, followed by a vote on the primary amendment (whether amended or not), followed by a vote on whether or not to adopt the main motion. For an illustrative scenario, see infra text accompanying note 61 .

All the sources listed in note 23 , supra, use this motion-and-amendment process. See, e.g., H. Robert, supra note 1 , at $108-40$; $J$. Tilson, supra note $23,41-46,72-85$.

40 For a short introduction to the concepts underlying the social choice literature, see $W$. Riker \& P. Ordeshook, supra note 27 , at 78-114. A more comprehensive discussion is contained in A. Sen, Collective Choice and Social Welfare (1970). There have been a number of articles exploring the relationship between various topics in law and the difficulties involved in making coherent group decisions. See, e.g., Easterbrook, Ways of Criticizing the Court, 95 Harv. L. Rev. 802 (1982) (relating social choice concepts to the Supreme Court); Epstein, Voting Theory, Union Elections, and the Constitution, in Due Process: Nomos XVIII supra note 12, at 333; Levine \& Plott, Agenda Influence and its Implications, 63 Va. L. Rev. 561 (1977) (examining the importance of order); Roin, United They Stand, Divided They Fall: Public Choice Theory and the Tax Code, 74 Cornell L. Rev. 62 (1988). 
and appear arbitrary because they depend on the order in which alternatives are considered. The paradox is surely one of the best known insights or topics in the social sciences. ${ }^{41}$ If person $A$ orders three alternatives (from best to worst) $123, B$ orders them 231, and $C$ orders them 312 , then 1 defeats 2 (because $A$ and $C$ will vote for 1 over 2 ), 2 defeats 3 ( $A$ and $B$ will vote for 2 ), and 3 defeats 1 ( $B$ and $C$ will vote for 3). An individual with such intransitive preferences, preferring 1 to 2,2 to 3 , but 3 to 1 , would probably be regarded as irrational. But the reality of aggregating individual preferences is that a set of rational individuals can create inconsistent collective results. No voting method guarantees an escape from this paradox; collective decisionmaking sometimes simply yields intransitive, disordered, or incoherent results. If individuals with these preferences vote repeatedly, there will be "cycling" because after 3 defeats 1,2 can still defeat 3 , and voting can continue indefinitely without an equilibrium. If such cycling is stopped by a rule forbidding the reintroduction of defeated propositions, ${ }^{42}$ then the order of consideration essentially determines outcome. If the group first votes on 1 versus 2 ( 1 winning), 3 wins in the second round. If 2 v. 3 is voted on first ( 2 winning), 1 will emerge in the next round. And, finally, if 1 v. 3 is voted on initially, 2 will defeat 3 in the second round. Alternatively, if the voting method calls for a proposition to be considered on its own, and implicitly, against all other alternatives, then the second proposition considered, whichever that may be, also wins. ${ }^{43}$

41 See D. Black, The Theory of Committees and Elections (1958) (includes history and discussion of collective choice theory's beginnings, and reproductions of the early works); Sen, Social Choice and Justice: A Review Article, 23 J. Econ. Literature 1764, 1765 n.7 (1985) (commenting on the explosion of social choice literature and noting that the "number of books and papers published in formal social choice theory has now certainly exceeded a thousand, the bulk of it coming in the last decade and a half").

42 In the amendment process under Robert's Rules, for example, a defeated amendment ordinarily may not be reintroduced. See H. Robert, supra note 1, at 116-17 ("After the assembly has voted that certain words ... shall, or shall not, form part of a pending resolution, it is not in order to make another motion to Amend that raises the same question of content and effect." (emphasis deleted)). See also supra note 28 (discussing the difficulty of reconsideration, particularly under Robert's Rules, of propositions that have already been decided).

43 In this example, the importance of order is shown with "sincere" voting, as opposed to "sophisticated" voting. Sincere voters always select the highest ranking option in their preference scale. Sophisticated (or strategic) voters are assumed to know the preferences of all voters and vote to accomplish the end result highest in their preference scale. A situation that yields cycling, that is, a situation where a voting paradox exists, will be paradoxical under 
This paradox was apparently first noted in the late eighteenth century and then rediscovered in the nineteenth century, but each of the pioneering mathematicians in this field was preoccupied with solving the paradox. ${ }^{44}$ Each tried to develop rules that would overconie cycling and insure coherent outcomes. ${ }^{45}$ The subsequent intellectual history of the matter can be (grossly) summarized as follows. In the

either sincere voting or sophisticated voting. See generally R. Farquharson, Theory of Voting 17-19, 30-44 (1969) (discussing sincere, straightforward, strategic, and sophisticated voting); A. Sen, supra note 40 , at 192-96 (discussing difficulties in devising systems of expression of individual preferences for the purpose of collective choice).

Given the preferences used in the text's illustration ( $A$ 's preference order is $123, B$ 's is 231 , and $C$ 's is 312 ), the order of the voting will still determine the outcome even if voters are sophisticated. If the group votes on 1 v. 2 first, the winner under sincere voting will be 3 . However, with sophisticated voting, person $A$ will vote counter to his true preference in the first round (that is, vote for 2 over 1 ) because $A$ realizes that the end result (the adoption of proposition 2) will be better for him than the end result given by sincere voting in the first round (the adoption of proposition 3). For identical reasons, sophisticated voting will yield a different result than will sincere voting if the first round is 2 v. 3 or 3 v. 1 .

\begin{tabular}{ccc} 
First round & \multicolumn{2}{c}{$\begin{array}{c}\text { Ultimate Winner } \\
\text { Sophisticated Voting }\end{array}$} \\
\hline 1 v. 2 & 3 & 2 \\
2 v. 3 & 1 & 3 \\
3 v. 1 & 2 & 1
\end{tabular}

For more on sincere versus sophisticated voting in this context, see $\mathbf{R}$. Farquharson, supra, at 17-23. An analysis of the strategies involved in nonsincere voting is found in W. Riker, Liberalism Against Populism 137-69 (1982).

An enormous body of literature has developed that cxplores various aspects of strategic, or sophisticated, voting. Elements of that literature which are particularly relevant to some of the ideas in the present Article include Moulin, Prudence Versus Sophistication in Voting Strategy, 24 J. Econ. Theory 398 (1981) (discussing strategies of voters with no information about other voters' preferences and voters with full information about these preferences); Pattanaik, Threats, Counter-Threats, and Strategic Voting, 44 Econometrica 91 (1976) (discussing ability of single voters to manipulate some otherwise sincere and stable voting situations); Wilson, Forward and Backward Agenda Procedures: Committee Experiments on Structurally Induced Equilibrium, $48 \mathrm{~J}$. Politics 390 (1986) (experiment suggesting that "backward voting," as in the motion-and-amendment process, protects the status quo while "forward voting" (last amendment voted on last) does not).

44 At best these mathematicians tried to deal with (rather than solve) the problem of cycling preferences by toying with the method of voting. None explored the question of when such preferences might arise or what determined outcomes in their presence. See infra note 45.

45 In eighteenth century France, Borda, Condorcet, and Laplace tried to come up with ways to assure the election of the candidate or option with the "most support." Borda's count, or scoring, system considered each voter's preference order, or ranking, of the candidates; Condorcet's system highly recommended head-on comparisons; and Laplace's system weighted the (cardinal) amount of merit each voter assigned to each candidate. For some favorable discussion of the "stability" (in the face of one voter's changed rankings) of the 
late 1940's Duncan Black first realized and wrote about the theoretical significance of the voting paradox. Black first shifted the focus from trying to avoid the paradox with mechanical rules to accepting its existence and assessing its reach. Having perceived that voters' preferences do not necessarily determine outcomes, Black sought to discover what else might determine outcomes. He uncovered the importance of "agenda setting"; in the scenario above, for instance, whichever proposition is withheld in the first round of voting will eventually win. ${ }^{46}$ Black also recognized the importance of "singlepeakedness," which, very. roughly speaking, reflects the observation that the voting paradox arises when voters' preferences are not all aligned on one scale but rather reflect different influences. ${ }^{47}$ If $A$ simply wants inore money spent on a highway prograin and $B$ wants less and less money spent on such a program, and the other voters similarly array their preferences on a single spectruin, no paradox will arise. The pardox can only arise when a voter least (or most) prefers a "medium" expenditure.

Black's work ushered in a period, continuing to this day, during which enormous attention has been paid to the paradox and, more generally, to the iinpossibility of constructing a "coherent" collective decisioninaking process. Kenneth Arrow showed that, given certain conditions, it is impossible-whether through majority or any other

"Borda count," see D. Mueller, Public Choice 61-64 (1979); H. Nurmi, Comparing Voting Systems 66-80 (1987).

In late nineteenth century and early twentieth century England, Dodgson, Nanson, and Hallet also worked to solve the problems caused by the paradox of voting. Dodgson (more widely known as Lewis Carroll) believed he had come up with a satisfactory way of dealing with cyclical majorities in A Method of Taking Votes on More Than Two Issues (1876). Nanson, in 1907, preferred his method of first taking into account voter preference orders and then repeatedly reducing the number of candidates after making calculations based on the voters' preferences. See generally D. Black, supra note 41, at 156-90 (discussing the history of the mathematical theory of committees and elections).

46 D. Black, supra note 41 , at $39-40$ ("When the ordinary committee procedure is in use, the later any motion enters the voting, the greater its chance of adoption." (emphasis deleted)).

${ }^{47}$ The term "single-peaked" reflects the idea that voters' preferences might be drawn on a graph with the possible alternatives on the horizontal axis and the order of preference on the vertical axis. An individual's preferences are single peaked if starting from the most preferred alternative, and moving either to the right or the left, the curve always slopes downward. A group is said to have single peaked preferences if it is possible to arrange the order of the alternatives along the horizontal axis so that all the individual preference curves are single peaked. See D. Black, supra note 41, at 14-45. For a summary and explanation of Black's work, see W. Riker \& P. Ordeshook, supra note 27, at 101; W. Riker, supra note 43, at 124-27. See also infra note 153 . 
method of aggregating individual preferences-to assure that social outcomes will not be paradoxical. ${ }^{48}$ Amartya Sen developed the notion that majority rule will be transitive, or coherent, when preferences are "value-restricted"-that is, when there is some alternative which each individual never ranks as either best, or worst, or medium. ${ }^{49}$ Thus, in the earlier example where the three individuals' rankings were 123,231 , and 312 , each alternative has every possible ranking. If the rankings were 123, 213 (instead of 231), and 312 so that alternative 1 was never "worst," the paradox would not be confronted. Alternative 1 could defeat 2, and 2 defeats 3 , but 3 would not defeat 1 .

With these great insights in place, an enormous research effort was set in progress. Work has been done on the degree to which cultural uniformity generates single-peakedness or value-restricted preferences. ${ }^{50} \mathrm{~A}$ good deal has been made of the observation, noted earlier, that no voting paradox arises when there are only two alternatives in any voter's ordering because preferences are necessarily singlepeaked. $^{51}$ Thus, well-disciplined two-party legislatures, run-off elections, and even constitutional provisions, might successfully suppress evidence of the paradox. ${ }^{52}$ And much has been written about the pos-

48 See K. Arrow, Social Choice and Individual Values (1951); W. Riker, supra note 43, at 115-36 (excellent discussion of Arrow's theorem); A. Sen, supra note 40, at 33-46 (giving what is generally considered to be a quite elegant proof of Arrow's "impossibility theorem").

See also M. Dummett, Voting Procedures 4 n.1 (1984), which stresses that "Arrow's possibility theorem (more exactly called an impossibility theorem) is so fundamental to the subject that he is often credited with having been the modern initiator of it, especially since his basic notation has become standard. This is unfair to Black, who was the real twentiethcentury pioneer of the theory of voting, as well as a diligent researcher into its earlier history."

49 See A. Sen, supra note 40 , at $166-86$.

so See W. Riker \& P. Ordeshook, supra note 27, at 105 (suggesting "the conventions and ideals of a culture are "value-restrictive" " and "the single-peaked preference curves reflect a cultural uniformity about the standard of judgment, even though people differ about what ought to be chosen under that standard"); A. Sen, supra note 40 , at 165 ("Individual preferences are determined not by turning a roulette wheel over all possible alternatives, but by certain speciflc social, economic, political, and cultural forces."); Coombs, The Theory of Data (1964) (showing that "the existence of single-peaked preference curves is [dependent on] ... the existence of a common qualitative dimension along which individual preferences can be ordered").

51 See W. Riker, supra note 43 , at 59 ("Simple majority decision on binary alternatives is consistent with the democratic purposes of voting ...; it is fair to all voters ...; and it is fair to all candidates....").

52 See id. at 64 (Although a vote between two alternatives seems fair, "it cannot be fair in a democratic sense because the imposition of binary alternatives is itself unfair."); id. at 41 
sibilities and the evidence of strategic behavior among well-informed, "sophisticated" voters. ${ }^{53}$ In the previous example, if $C$, whose preferences are 312 , knows that alternative 1 will be voted on first and that if it loses 2 will then win, $C$ may vote for alternative 1 in the first round, even though $C$ prefers 3 , in order to prevent the emergence of 2. To the extent that $A$ and $B$ may also recognize such possibilities, it is easy to see that a complicated game is in the making. Finally, many writers have sought to estimate how often voting paradoxes occur in real decisionmaking, or how often players can contrive convenient paradoxes. ${ }^{54}$

This very light sketch of the collective choice problem is intended to emphasize one point about procedural rules and then to raise the central question of this Article. Parliannentary procedure might be regarded as clever and fair if it enables individuals whose collective preferences do not create a paradox to reach the desired (majority) outcoine, perhaps in a way that allows participants to feel positively about the process. ${ }^{55}$ But when preferences are not so conveniently arrayed, rules of order are likely to determine outcoines-and no expert in choice theory can inake it otherwise. If, for instance, a group finds itself in a situation where the second proposal to be presented will einerge as the "majority's will," then the chair's ability to recognize speakers and proposals is likely to be outcome determi-

("simply because we force ourselves into a binary choice should not obscure the fact that we really start out with many alternatives and that we can never be certain that our institutions have narrowed the choice down to the right pair for us to choose between").

53 See, e.g., M. Dummett, supra note 48, at 210-42; W. Riker, supra note 43, at 193-95 (discussing the seventeenth amendment to the United States Constitution); Gross, Conference Committees, Sophisticated Voting, and Cyclical Majorities, 4 Legis. Stud. Q. 79, $87-91$ (1979) (discussing 1975 Iowa farm legislation); Riker, The Paradox of Voting and Congressional Rules for Voting on Amendments, 52 Am. Pol. Sci. Rev. 349, 357 (1958) (discussing a 1953 United States House of Representatives appropriations bill).

54 See A. Sen, supra note 40 , at 163 (discussing a number of studies which attempt to determine "the probability of there being no 'majority winner" "); infra note 81 .

ss A Condorcet winner is an alternative which beats all alternatives in one-on-one comparisons. The participants are likely, I think, to feel positively about the process because more than half of them will have voted for the measure adopted and there is no other single alternative that is preferred by a majority of voters. In marked contrast, a number of other voting methods, discussed presently, can eliminate a Condorcet winner, resulting, it would seem, in negative feelings about the process since a majority could recognize its preference for a different alternative which would not lose in any one-on-one comparisons. For a discussion of the importance of the losers' feelings about the decisionmaking process, see Thibaut, Walker, LaTour \& Houlden, Procedural Justice as Fairness, 26 Stan. L. Rev. 1271 (1976). 
native. ${ }^{56}$ The rules can be neutral-for example, if either the chair is unaware of the individuals' preferences or, more affirmatively, there is a random process to determine voting order ${ }^{57}$-but they will still determine the outcome, because there is no collective preference independent of the rules of order. And the rules may occasionally be overridden by bargains among the parties. $C$ may pay $A$ and $B$ to do things $C$ 's way or, more generally, the parties may agree to choose among alternatives through an auction, or similar market mechanism. These bargains or auctions, however, are very much im the shadow of the voting rules because these rules determine the initial endowments, or positions from which bargaining takes place. ${ }^{58}$

56 One author goes so far as to maintain that, in the presence of cycling preferences and complete information, a perceptive chairperson can arrange for the selection of any outcome. McKelvey, Intransitivities in Multi-Dimensional Voting and Some Implications for Agenda Control, $12 \mathrm{~J}$. Econ. Theory 472 (1976). This is easiest to imagine in situations where there are infinite alternatives which might be proposed, and which might divide majority coalitions. See W. Riker, supra note 43, at 192; Banks, Sophisticated Voting Outcomes and Agenda Control, 1 Social Choice \& Welfare 295 (1985).

57 Interestingly, random processes are virtually never found in parliamentary law. It is possible that the authorities on parliamentary procedure have been disinclined to try procedures which cast doubt on the elegance of majoritarian rule. Emphasizing that group decisionmaking in a democracy is sometimes the product of arbitrary or random features might undermine the high regard in which the decisionmaking process is held. Moreover, the decisionmaking generated by a process which includes some random element will rarely be reproducible, whereas other forms of decisionmaking may seem more stable in the sense that, so long as the agenda, or order of presentation, is kept the same, results will often be reproducible. But inasmuch as this order is often itself a randomizing element, I do not find the irreproducibility of randomized decisionmaking terribly unique.

58 Put in Coasian terms, endowments affect bargains (so that rules can matter) and voting is about endowments. If a majority of voters prefers alternative 1 over alternative 2 , then it is of course possible for a minority to display its intensity of preference (or simply its greater wealth) either by bargaining for votes or, ex post, by purchasing alternative 2 directly. A different coalition may then purchase a different outcome, and so forth, but at some point in the absence of transaction costs such an auction will produce a winner. But those who buy votes or outcomes eventually run into budget constraints so that the votes themselves are valuable and voting procedures affect real outcomes. Those who have procedures and $\$ \mathrm{X}$. on their side can get their way much more often than those who have only $\$ \mathrm{X}$. We (correctly) think of the rich and powerful as courting, or sponsoring, the chairperson of a powerful committee rather than as being indifferent to the chair and bargaining around whatever the chair is inclined to do.

At a more general level, in many circumstances bargains do not override votes because of significant transaction costs. While this is nothing more than a specific example of the most familiar response to Coasian skepticism about the importance of rules, there is reason to think that transaction costs are especially significant where voting rules are in effect. After all, the fundamental question in the spirit of the Coase theorem is not why bargains do not overwhelm voting rules, but rather why people agree or bargain in the first place to decide things by votes 


\section{B. The Dissatisfaction Hypothesis}

The publication and study of parliamentary procedure in the United States peaked in the late nineteenth century and early twentieth century at a time when it is probable that not even the most educated or thoughtful citizen comprehended the voting paradox. And, in fact, not a single guide to parliamentary law concedes the ultimate effect of procedural rules on outcomes and not a single one mentions or seems to notice the voting paradox. Indeed, most parliamentary guides contain statements which reveal either a total lack of recognition of cycling problems or a desire to suppress such recognition. ${ }^{59}$ Nevertheless, I think it likely that Luther Cushing, Henry Robert, and others who had extensive experience at meetings must have occasionally sensed the importance of procedure-even when all (or no) participants were knowledgeable about parliamentary law and

rather than bargains. The answer suggests that voting rules are in place precisely where transaction costs are significant.

It may be useful to point out that even apart from endowment effects, a variety of transaction costs are likely to interfere with most attempts to escape the instability of cycling preferences through the use of auctions. Participants in auctions learn quickly that collusion can be quite profitable; if $A$ and $B$ can bid up the price of something $C$ eventually acquires, while refraining from competition against one another, they can get more for their chips than can $C$. Of course, such a coalition is unstable, as $C$ (or $A$ or $B$ ) will try to induce defection and the formation of a different coalition. The gist of this complicated matter is that auctions do not guarantee the emergence of anything like transitive and stable preferences. And the larger point is that procedural rules are likely to matter in many situations where preferences are not value-restricted.

Finally, there is some evidence that one kind of "bargain" which might be reached is one which seems to offer a fair compromise among the cycling preferences. To the extent that this happens, procedural rules seem not to matter and outcomes may be predictable even in the face of non-value-restricted preferences. See Farber \& Frickey, Legislative Intent and Public Choice, 74 Va. L. Rev. 423, 432-37 \& n.31 (1988) (expecting some stability even in the face of cycling preferences and citing some supportive empirical work). Of course, as the examples in the text illustrate, preferences sometimes cycle precisely because or almost because it is not obvious which position is a compromise. For some discussion of compromise among friends and, perhaps, colleagues who expect to deal with one another repeatedly, see infra text following note 176.

59 See, e.g., L. Bridge, supra note 23 , at v ("Parliamentary law is impartial, guaranteeing equal rights to all. ... It offers participation to all, imposes responsibilities on all, serves the best interests of all, and saves the time of all."); A. Sturgis, supra note 23, at 3-4 ("The philosophy of parliamentary law is constructive. It is designed to facilitate and to help rather than to hinder or to obstruct. ... Its aim is not to confuse, to mislead, or to thwart an honest expression of the majority's will."). 
maneuvers. ${ }^{60}$ In particular, they must have noticed the occasionally decisive effects of the order in which speakers were recognized and in which motions and amendments were proposed. Continuing with the example developed in the previous section, if the first speaker moves alternative 1 , a second proposes an amendment that would turn 1 into 2 , and a third proposes an amendment to the amendment such that, if passed, alternative 3 would emerge, then, as seen earlier, the order in which votes are taken will essentially determine the outcome because the voters' preferences are not single peaked. Parliamentary law normally calls for the secondary amendment to be voted up or down first $^{61}$ and, as above, with $A, B$, and $C$ preferring 123,231 , and 312 respectively, 3 will be defeated (because $A$ and $B$ prefer the amendment (2) without the secondary amendment (3)), and 2 will then be defeated with 1 surviving (on the strength of $A$ and $C$ 's votes). ${ }^{62}$ If the speakers were recognized in a different order, so that a member preferring 1 proposes it as an amendment rather than as the main motion, 1 would obviously have been defeated..$^{63}$

I am prepared to accept the notion that only a genius could proceed from sensing discomfort with, or the importance of, the voting order to grasping the impossibility of escaping from the influence of order.

60 Some of the parliamentary guides put a (marketing) premium on the idea that to protect one's rights and democratic power, each citizen must become adept at parliamentary maneuvering. See, e.g., F. Kerfoot, supra note 23, at 13 (Without recognized rules "each individual will act according to his own inclination; no one will know what his rights are, nor how he is to proceed; ... [ [business] will be done amid confusion and disorder, and will likely be controlled by the shrewdest or the loudest."). With or without such skill, a fair number of decisions still depend on the order in which votes are taken. Robert and other parliamentarians may have focused their observations on instances in which those educated in parliamentary rules outmaneuvered their opponents, but surely they must have noticed the occasional or even frequent importance of the rules themselves. This conjecture about Robert and Cushing is influenced by my own experiences and anecdotal evidence from colleagues and acquaintances prior to any formal encounters with books or instructors' descriptions of cycling majorities or Arrow's impossibility theorem.

61 See, e.g., H. Robert, supra note 1 , at 121 (illustrating vote on secondary amendment in order to first perfect or leave unchanged a (not yet voted on) primary amendment).

62 With sophisticated voting, the proposal voted on earlier (and proposed later) is advantaged. If $B$ can see that with sincere voting 1 will survive, he will favor 3 over 2 in the first round, and 3 then defeats $I$ in the second round. Thus, the last proposal, 3 , emerges. $A$ may try to arrange a deal with $B$ in which 2 prevails over 3 in return for $A$ 's support of 2 in the second round. But this requires $B$ to trust $A$. Either way, the order in which proposals are brought up for consideration affects the final result.

63 Because 1 loses to 3 with sincere voting, in order for 1 to survive, 1 must be brought into the consideration process after 3 is excluded. 
But intuition and casual (modern) evidence rather strongly suggest that at least some participants must have noticed the importance of order, or procedure. In particular, I like to imagine that experienced organizers or voters themselves might have expressed dissatisfaction with the outcome of a set of votes when it was later apparent, perhaps through informal, post-adjournment discussions, that a majority preferred a given alternative to the one decided on by formal vote. $\mathrm{My}$ basic evolutionary hypothesis or conjecture is that such dissatisfaction prompted tinkering with the rules of order. ${ }^{64}$ Innovation often took place where procedural rules affected outcomes because the "majority will" appeared thwarted rather than enabled by parliamentary law. Armed with a modern understanding of the voting paradox, it is easy to see that this innovation was doomed, and that any different set of procedural rules would also lead to dissatisfaction (and further tinkering). But it is easy to imagine that even as recently as fifty years ago an experienced observer of parliamentary procedure might have seen a majority thwarted in a particular situation and modified a rule to ensure that in the specific situation that majority would have prevailed.

I will distinguish between two basic kinds of dissatisfaction before illustrating that variety within parliamentary law is largely connected with those rules that determine outcomes in the presence of cycling majorities. "Unavoidable dissatisfaction" occurs in situations such as the example already discussed. Assuming $A, B$, and $C$ 's preferences are 123, 231, and 312 respectively, and 1 emerges as the group's

${ }_{64}$ This is not to say that such tinkering was inevitable. Dissatisfaction might have led to more significant changes than those discussed in this Article. Moderate changes might have included more (or less) delegation to committees or to elected leaders (as seems periodically to occur in the United States Congress), more reliance on supermajorities, and developments which limited choices to two alternatives. Still more significant changes might have included movements away from democratic decisionmaking itself. Dissatisfaction, in short, could have led more to revolution than to evolution. As must already be apparent, my focus in this Article is on a positive theory of voting rnles. I do not pretend to explain the occasional appearance of larger or structural changes in decisionmaking processes nor do I claim that the rules I describe were somehow the only possible rules that could have arisen.

Nevertheless, one constraint on changes developed in this Article is that voting rules reflect a sensitivity to manipulation by a chairperson or other participant. Some roads not taken, such as supermajoritarianism, might therefore be explained as unattractive even to dissatisfied coalitions on these grounds. In the case of supermajority votes, for instance, the form of a motion obviously matters a great deal, see infra text following note 113 , and the chair's power to call on someone who will make a motion, which is at odds with the chair's preferences and which then can be defeated by a less-than- $50 \%$ coalition, is obviously quite significant. 
choice, if $B$ and $C$ compare notes and become aware of their joint preference for 3 over 1 , they understandably will be disturbed by 1's emergence in a system which claims to be governed by majority decisionmaking. But, as we have seen, this combination of preferences makes such dissatisfaction unavoidable because if 2 emerges, $A$ and $C$ will be dissatisfied that 1 did not win, and if 3 emerges, $A$ and $B$ will be disturbed that 2 did not prevail. Voters who are educated in collective choice theory might agree on random devices for determining the outcome among the alternatives in such situations. ${ }^{65} \mathrm{I}$ am unaware, however, of any such arrangments and, indeed, a popular academic conclusion about cycling majority outcomes is that the chair, or other "agenda-setter," is a powerful figure because so much depends on the order in which speakers are recognized. ${ }^{66}$ In any event, inasmuch as the percentage of participants at meetings who understand the voting paradox has always been minuscule, it is easy to imagine that (unavoidable) dissatisfaction arises when it becomes apparent that a majority prefers a known alternative to that which emerged through the prevailing rules of order, and this dissatisfaction can generate changes in the rules. ${ }^{67}$

A very different kind of majority disappointment might be labeled "avoidable dissatisfaction." Imagine that $D, E$, and $F$ 's preferences on some matter are 456,564, and 654. Alternative 5 defeats 4 and 6 in one-on-one competition, although quite plainly no alternative enjoys a simple majority of the first-place votes. Such a winner (as alternative 5) is known as a Condorcet choice and is obviously quite attractive. ${ }^{68}$ It may sometimes seem tempting to put aside a Condorcet winner in favor of some other choice, perhaps because a minority intensely dislikes the Condorcet alternative and no voter objects strongly to the non-Condorcet alternative. Although I will touch on this possibility in Part III, it is reasonable to proceed, as does virtually

\footnotetext{
65 See supra note 57.

66 See supra note 56. Of course, when the chair has no knowledge of what particular speakers plan to propose, the chair's power of recognition can serve as a random ordering device.

67 These dissatisfied participants may or may not recognize that after such changes there will be a different combination of dissatisfied participants, including some of their own number. Dissatisfaction is in this sense a "simple" rather than a "sophisticated" concept.

68 For discussion of the distinctions among the concepts of Condorcet winners, Condorcet conditions (a choice meets the condition if no alternative defeats it by a simple majority), and related ideas, see $\mathrm{H}$. Nurmi, supra note 45 , at $38-40$.
} 
the entire collective choice literature, ${ }^{69}$ under the assumption that a Condorcet winner is very desirable. If parliamentary rules and the group's preferences combine to yield 6 as the group decision, $D$ and $E$ would be understandably dissatisfied and skeptical of the rules' ability to elicit the will of the majority. The preferences do not yield cycling majorities because here no alternative defeats $5 ; D$ and $E$ 's dissatisfac-

69 Black, in initiating modern social choice theory, declared that "[o]ur own position is that our faith in the Condorcet criterion is stronger than in any other, but it is not an unqualified faith," and that "it appeals, perhaps via mathematical symmetry, to our sense of justice. The reasons may not seem overwhelmingly convincing, but we are moving in a region where all considerations are tenuous and fine-spun; and the claims of the Condorcet criterion to rightness seem to us much stronger than those of auy other." $D$. Black, supra note 41 , at 58 . The large volume of literature discussing how to proceed when there is uo Condorcet winner evidences the fundamental place in social choice theory which the desirability of a Condorcet winner occupies. Most writers accept almost as a given that the ability not to miss a Condorcet winner is a basic test when evaluating a voting procedure. See, e.g., W. Riker, supra note 43, at 100 (listing the Condorcet criteria as part of the "criteria for judging voting methods" and commenting, "according to the first 'deeper' requirement of fairness and consistency, the Condorcet criteria, if an alternative beats (or ties) all others in pairwise contests, then it ought to wiu. This notion is closely related to the notion of equality and 'one man, one vote,' in the sense that, when an alternative opposed by a majority wins, quite clearly the votes of some people are not being counted the same as other people's votes."). See generally Kramer, supra note 26 (discussing various criteria and procedures, their relationships to each other, as well as their advantages and disadvantages). A reader who is skeptical about the lofty position occupied by the Condorcet criterion may find it useful to note two attributes of Condorcet winners: strategic voters will most often find their way to Condorcet winners, see infra uote 136 , and, as compared to other ideals, it is relatively difficult to unseat a Condorcet winner by introducing new alternatives for voters to consider. For some discussion of the attractiveness of the Condorcet winner, see Kramer, supra note 26, at 265-76.

The Condorcet concept has at least two well-known defects: Preferences do not necessarily, or even usually, deliver a Condorcet winner, and the concept does not take into account intensity of preference. The former defect is what makes voting paradoxes and cycling majorities possible. In light of this possibly common occurrence, see supra uote 54 , many authors have tried to extend the Condorcet concept by suggesting methods for choosing a winner in the event of a voting paradox. See, e.g., Kramer, supra note 26, at 271-74; Young, Extending Condorcet's Rule, 16 J. Econ. Theory 335 (1977).

The trouble with not taking intensity into account-and most voting procedures do not-is that an alternative may be a Condorcet winner even if it is only marginally preferred by a bare majority and intensely disliked by a large minority. Many systems try to correct this problem by giving each alternative some sort of score (either tied to its original rank or not). Indeed, the Borda method (giving each alternative points based on its ordinal ranking by the voters and then totalling these points) was developed earlier thau and exerted influence on Condorcet's work. See D. Black, supra note 41, at 156-59. These systems, however, create new problems at least as fast as they find solutions for old ones. W. Riker, supra note 43, provides a very thorough discussion of so-called "positional methods of voting" and "utilitarian methods of voting" that incorporate degree of intensity. The point remains, of course, that there is no "right" decision method that best reveals the will of the majority. 
tion is thus avoidable because the emergence of alternative 5 does not generate another majority's dissatisfaction.

This Article will return to these two types of dissatisfaction. For the present, however, it is sufficient to note that both forms of dissatisfaction could have encouraged tinkering with the procedural rules that seem to produce the distasteful results.

Equipped with the insights of Black and Arrow or with the literature now in existence, the various codifiers of the rules of order might have explained the insolubility of certain problems and innovated only where Condorcet winners were defeated. In reality, I think they simply tinkered when majorities seemed thwarted. But remarkably, they seem to have divined the advantage of not making changes that would reduce the chances of finding a Condorcet winner and increase the level of avoidable dissatisfaction. It is possible that Robert and other writers were quite consciously aware of the voting paradox, either because it was better understood by educated or politically astute persons than written records now suggest or because earlier academic work was less obscure than it now seems. ${ }^{70}$ One can even imagine a silent conspiracy in which these writers suppressed understanding of the occasional incoherence of majority rule and the power of the agenda setter to help convince the masses that democracy and formality are flawless treasures. These scenarios seem unlikely, and, in any event, of the central arguments in this Article only the suggestion that a particular type of "dissatisfaction" was the engine of evolution depends on the motives and insights that are attributed to the drafters of parliamentary rules. ${ }^{71}$

70 Virtually all modern scholars appear to be familiar with the early work of Borda, Condorcet, Dodgson, and others, but only through Duncan Black's descriptions and reproductions of the early work. Black's work quite plainly came later than most of the authorities on parliamentary law. Moreover, it is clear that Black, in the 1940's, carried out an energetic search simply to find much of the earlier work. See, e.g., D. Black, supra note 41 , at xi (only one known copy of a work by Dodgson). It is extremely unlikely that the authorities developing parliamentary law in the years 1840-1920 would have known about this literature.

71 It may be useful to note that the evolutionary argument developed in this Article depends mostly on the presence of cycling majorities and not on the deeper impossibility of solving the voting paradox. I am fairly convinced that the codifiers of parliamentary law had inklings about cycling and the importance of procedure, but nothing more.

Inasmuch as the dissatisfaction hypothesis suggests that tinkering, innovation, or "variety" in law might be the result of disappointment with the effects of existing legal rules, it is tempting to insist that the variety discussed presently in Section C of Part II, infra, is much like that found elsewhere in law where reasonable people could disagree about the effects of 


\section{Variety in Parliamentary Law}

\section{Filling Blanks}

It is useful to begin relating specific parliamentary rules to the problem of collective choice with a relatively dry example, the practice of "filling blanks." Imagine that a legislative meeting is governed by Robert's Rules and that a member is eager to see a substantial sum appropriated toward the construction of a new highway. The member may be eager to allocate up to $\$ 20$ million to the project, but may not want to lose to a majority containing both members opposed to the project and members opposed to any expenditure of more than $\$ 5$ or $\$ 10$ million. If the members' precise preferences are unknown, a motion may be made "to proceed with the highway project at a cost not to exceed \$-."72 The idea is to fill in the blank through subsequent votes after the initial motion is passed. But, assuming the initial motion is passed, how should the blank be filled? When there are more than two alternatives-and obviously there are infinite numbers to insert in the blank - the voting paradox can arise if preferences are not value restricted. It would hardly be extraordinary for five voters to have the following preferences for expenditures of $1,5,10$, and 20 million dollars:

\begin{tabular}{lrrrrr} 
Voter: & $A$ & $B$ & $C$ & $D$ & $E$ \\
\hline 1st choice & 20 & 1 & 10 & 5 & 20 \\
2d choice & 10 & 5 & 1 & 20 & 1 \\
3d choice & 1 & 20 & 5 & 10 & 10 \\
4th choice & 5 & 10 & 20 & 1 & 5
\end{tabular}

One might imagine $E$, for example, as believing that a superhighway (at a cost of 20) is wise, but that some lesser expenditures will improve traffic flows so little as to be not worthwhile. $E$ 's second choice is therefore an amount sufficient only to repair potholes on the existing narrow road (1). If more than this is to be done, $E$ prefers

given rules. See Levmore, Rethinking Comparative Law, supra note 3, and Levmore, GoodFaith Purchaser, supra note 3. I do not, however, wish to emphasize this larger conception, primarily because with "unavoidable dissatisfaction" legal systems may choose to suppress evidence of incoherence. See, e.g., infra text accompanying note 138 . There is, therefore, an evolutionary enzyme in the law of majority decisionmaking which is not present, for instance, in the law about comparative negligence, where evolution may simply reflect different-but not hopeless-strategies of resolving a difficult problem. See Levmore, Rethinking Comparative Law, supra note 3 , at 242-43, 276-79.

72 H. Robert, supra note 1, at 136. 
widening the road (10) to simply repaving it (5). $C$, on the other hand, believes the road should be widened, but adamantly opposes a very large expenditure. Similar rationalizations can be advanced for each ordering of the four alternatives.

If $A, B, C$, and $D$ are recognized in that order and each moves to fill in the blank with his first choice, and a proposal once defeated cannot be reintroduced, ${ }^{73}$ only $A$ and $E$ will vote for $A$ 's proposal of 20 , and only $B$ supports his own proposal of 1 , but $C$ 's proposal of 10 will then win three votes $(A, C$, and $E)$ to two. Were recognition to begin with $B$, only $B$ would vote for his proposal of $1, C$ 's proposal of 10 would only get $C$ 's vote, and 5 would then secure a majority ( $B$ and $C$ joining $D$ ) when $D$ moved its insertion. The voting order obviously has a great deal to do with which outcome emerges.

Robert's Rules suggests that in filling blanks "members have an opportunity to weigh all choices before voting and to vote on them in a fair and logical order."74 The rules advise that the proposed entries be arranged "so that the one least likely to be acceptable will be voted on first, and so on."75 If motions for expenditures of 5 and 10 (both winners above) are introduced first, because each enjoys only one first and one second place ranking, they will be defeated and 20 will emerge because $A, D$, and $E$ prefer it to 1 . After the meeting, however, a majority of voters $(B, C$, and $D)$ may be disturbed to learn that they all preferred 5 to 20 , despite 20 's emergence as the collective choice. The "logical" method of excluding 5 early on prevented the direct comparison of 5 and 20.

Robert's Rules also suggests that since the character of the first motion with a blank is to spend money it "indicates that the amounts should be arranged and voted on in order from the highest to lowest."76 Strategic voting aside, 1 will win if the group follows this plan, because 20,10, and 5 will each fail to receive three votes (only $A$ and $E$ vote for 20, only $A$ and $C$ vote for 10 , and only $D$ votes for 5). Robert's two suggestions obviously can lead to different outcomes, and if the group votes on these numbers as amendments, rather than as blank fillers, any outcome is possible depending on the order of

\footnotetext{
73 See supra note 42.

$74 \mathrm{H}$. Robert, supra note 1 , at 136.

75 Id. at 138.

76 Id.
} 
recognition. ${ }^{77}$

What if under the rules of order voting proceeds from lowest to highest? Alternatives 1,5 , and 10 would now lose-only $B$ would vote for 1 , only $B$ and $D$ for 5 , and only $C$ for 10 and 20 would emerge as the winner, whereas 1 emerged under the highest-to-lowest plan. The substance of the suggestions in Robert's Rules is neither logical nor illogical. The voting paradox is simply inevitable and the order in which votes are taken will matter. Robert might have: (1) incorrectly believed that the highest-to-lowest solution is best because rational voters always prefer to spend less money; (2) noticed that, if the chair were allowed to recognize speakers selectively, the chair could consciously influence outcomes-and preferred a less-preordained result; or (3) simply been unaware of the substantive importance of the procedural rule. Robert mentions only (1) in support of his rule, but the other two possibilities are plausible. ${ }^{78}$

Robert's rules work better when the preferences do not cycle. If, for instance, $A, B, C, D$, and $E$ were not voting on highway expenditures but rather on the maximum amount they would spend to settle a

77 In the examples in the text, all four outcomes are achieved. Under the motion-andamendment process, four different arrangements could also lead to four different results. For the examples below, assume that there is a main motion $(M)$, a primary amendment $\left(A^{1}\right)$, a secondary amendment $\left(A^{2}\right)$, and an alternative primary amendment $\left(A^{1 x}\right)$. The order of voting under Robert's Rules, see supra note 39 , would first pit the secondary against the primary, with the winner then compared to the main motion because two primary amendments can not be pending at once. Finally, the survivor of these first two rounds is tested against the alternative primary amendment. Consider the following four arrangements:

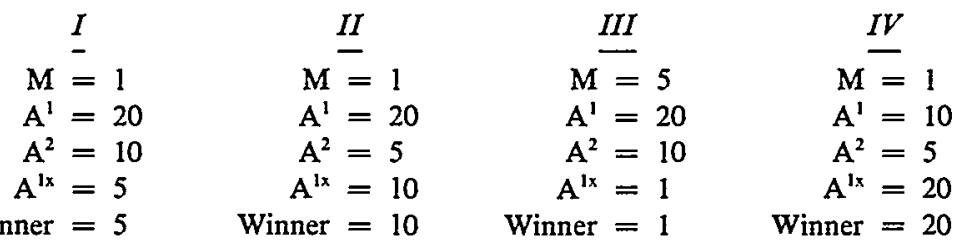

In I, $20\left(\mathrm{~A}^{\prime}\right)$ defeats $10\left(\mathrm{~A}^{2}\right)$ (only $C$ votes against) and then defeats $1(\mathrm{M})(A, D, \& E$ v. $B \&$ $C)$, but 20 then loses to $5\left(\mathrm{~A}^{1 \times}\right)(B, C, \& D$ v. $A \& E)$, so that 5 wins. In II, $5\left(\mathrm{~A}^{2}\right)$ defeats 20 $\left(\mathrm{A}^{\mathrm{1}}\right)$, as above, and then loses to $1(\mathrm{M})$ (only $D$ votes for 5$)$, but 1 then loses to $10\left(\mathrm{~A}^{1 \mathrm{x}}\right)(A, C$, $\& D$ v. $B \& E$ ), so that 10 wins. When the proposals are presented in the order recorded in III, $10\left(\mathrm{~A}^{2}\right)$ loses to $20\left(\mathrm{~A}^{1}\right)$ (only $C$ votes for 10 ) which then loses to $5(\mathrm{M})(B, C, \& D$ v. $A \& E)$, but 5 then loses to $1\left(A^{1 x}\right)$ (only $D$ votes for 5 ), so that 1 wins. Finally, in $I V, 5\left(A^{2}\right)$ loses to 10 $\left(\mathrm{A}^{\prime}\right)(A, C, \& E$ v. $B \& D)$ which then defeats $1(\mathrm{M})(A, C, \& D$ v. $B \& E)$, but 10 then loses to $20\left(\mathrm{~A}^{1 \mathrm{x}}\right)$ (only $C$ voting against 20 ), making 20 the fourth different winner in four distinct voting orders with the motion-and-amendment process.

78 See H. Robert, supra note 1 , at 138. 
strike by employees or to purchase a particular building, then it is most unlikely that anyone would exhibit preferences that were not single peaked. In these cases, voting "logically" would begin with the higher number.

Finally, Robert's both limits each member to one proposal for filling a blank ${ }^{79}$ and notes that the procedure for filling blanks allows the voters to weigh all choices rather than the maximum of three which is permitted in the open at any one time with the ordinary amendment process. ${ }^{80}$ The first of these features may do something to prevent contrived paradoxes and to generate Condorcet winners, ${ }^{81}$ and the

79 Id. at 137 (allowing a member to make more than one proposal only if he "receives unanimous consent to do so").

80 Id. at 136. In filling blanks, any number of alternatives may be proposed before the voting takes place. The motion-and-amendment procedure allows only the main motion, the primary amendment, and a germane secondary amendment to be under consideration when the voting begins. Robert disallows tertiary amendments because "it would make the parliamentary situation too complicated." Id. at 111. Robert seems to recognize, however, that complexity is inevitable because a member is allowed to announce "while a secondary amendment is pending, that if it is voted down, he will offer another secondary amendmentwhich he can then indicate briefly-in its place." Id.

The United States House of Representatives (and several books on parliamentary law infiuenced by the House rules, see, e.g., J. Tilson, supra note 23, at 74) allows up to five alternatives to be pending at once by allowing "substitute" amendments. A substitute amendment is an amendment which wholly replaces the primary amendment, as opposed to changing a part of the primary amendment. "[A]lthough amendments in.the third degree are not permitted, up to four amendments may be pending at the same time: an amendment to the bill, an amendment to the amendment, a substitute for the original amendment and an amendment to the substitute." Congressional Quarterly's Guide to Congress 344 (2d ed. 1976). If the original bill is considered an alternative, there can be, in this way, five alternatives under consideration at one time. In any event, the "blank-filling procedure" obviously allows more alteruatives to be considered simultaneously than any of the motionand-amendment procedures.

81 As the number of pending alternatives increases, there is a greater chance that there will be cycling and less chance that there will be a Condorcet winner. See D. Mueller, supra note 45, at 48; A. Sen, supra note 40, at 163-64; Kelly, Voting Anomalies, the Number of Voters, and the Number of Alternatives, 42 Econometrica 239 (1974); Kramer, supra note 26, at 267. The rule against multiple proposals from a single member may aim to prevent one member from intentionally creating a paradox by diluting the support of a popular measure through proposals which appeal to, and splinter off, factions supporting what would have been a Condorcet winner.

Another possible reason for this rule is to prevent manipulation of the voting order by a member. Consider the following situation where multiple proposals by a single member are permitted: A member correctly believes there to be three viable possibilities, 1,2, and 3, for an upcoming issue, and $45 \%$ of the voters support $1,45 \%$ support 2 , and $10 \%$ support 3 . Under the blank-filling procedure, a manipulative member, favoring option 1, should first propose option 2 and then propose option 1 . Option 2 will be put to a vote and receive only $45 \%$ of the 
second may be a simple timesaver. ${ }^{82}$ In any event, the blank-filling format is a form of "succession voting" where many proposals may be introduced and then voted on individually until one obtains majority approval, and not a form of motion-and-amendment voting where a secondary amendment competes with a primary amendment, with the survivor pitted against the original motion.

It is noteworthy that Jefferson's Manual of Parliamentary Procedure, which by default provides the House of Representatives rule on this subject, ${ }^{83}$ suggests that when the larger includes the lesser, as in the amount of a fine, consideration should proceed highest to lowest. ${ }^{84}$ And when the lesser includes the greater, as in the date the session shall adjourn, voting should proceed lowest to highest. ${ }^{85}$ Jefferson appears to miss the possibility that a member might prefer to adjourn by some special day, such as Thanksgiving, but if that fails might then wish to accomplish as much as possible and adjourn on the last day of the year. Thus, it is not impossible for the preference ordering to be November 22, December 31, and December 24, in which case there

vote. After its elimination, option 1 might then receive enough votes from former option 2 supporters to be adopted. Although this same manipulation could be accomplished with the cooperation of another supporter of option 1, the rule of one proposal per member makes manipulation much harder.

82 If, for example, seven alteruatives have some support among the members of a group, it would almost certainily be faster to use the blank-filling procedure since as soon as one proposal receives a majority the decisionmaking process is ended. This may happen after one or two votes are taken. Under the motion-and-amendment procedure, six votes can be required as long as there is not an early winner.

Moreover, when numerous pending alternatives are permitted, the chances of unfair exclusion of a proposal because of late recognition by the chair are reduced. Robert says that amendments cannot be proposed which "raise questions already decided." See supra note 28. If there were four possible alternatives, as in supra note 77, and either the secondary amendment or primary amendment were adopted, it would be possible for the fourth alternative, proposed either as an alternative primary amendment or as an alternative secondary amendment, to be ruled out of order. Under the blank-filling procedure, the fourth alternative would not suffer this disadvantage.

83 H.R. Doc. No. 279, 99th Cong., 2d Sess. 679 (1987) (Rule XLII of the House Rules).

84 T. Jefferson, supra note 23 , at 70 ("In all cases of time or number, we must consider whether the larger comprehends the lesser, as in a question to what day a postponement shall be, the number of a committee, amount of a fine, term of an imprisonment, term of irredeemability of a loan, or the terminus in quem in any other case. Then the question must begin a maximo.").

BS Id. at 70-7I ("Or whether the lesser includes the greater, as in question on the limitation of the rate of interest, on what day the session shall be closed by adjournment, on what day the next shall commence, when an act shall commence, or the terminus a quo in any other case, where the question must begin a minimo."). 
may not be a dominant outcome, and the result depends on the order of consideration. ${ }^{86}$ Jefferson's background rule, presumably applicable when neither the lesser nor the greater includes the other, is highest to lowest with a notation that the rule of Parliament "privileges the smallest sum and longest time" instead. ${ }^{87}$ There is, unfortunately, no reason given for this reversal of English practice.

Reed's Parliamentary Rules states that highest-to-lowest is the proper method for filling blanks, and notes that the normal practice in the House of Representatives is to proceed not by a special blankfilling procedure but by the usual amendment route. ${ }^{88}$ The Sturgis Standard Code of Parliamentary Procedure also switches away from the motion-and-amendment process and calls on all suggestions for filling blanks to be recorded (without seconds) and then for the chair to take votes beginning with the first proposed, until one receives a majority vote. ${ }^{89}$ But remarkably enough, Cushing, who predates Robert, draws on an "ancient rule" and calls for the votes "beginning with the least sum or longest time, as the case may be, and so on to the greatest sum or shortest time, or until the house comes to an agreement upon some one of the times or sums mentioned."90 Cushing goes on to note that, to the contrary, this country's legislative assemblies follow a "special rule" and vote first on the "largest (instead of the least) sum, and the longest (that is the furthest off) time."91 Gregg's Parliamentary Law follows Cushing and rules that suggestions for filling blanks need not be seconded and that voting proceeds from smaller to greater sums and from longer to shorter times. $^{92}$

86 There easily could be three factions: one most preferring Thanksgiving as an adjournment date, one least preferring Thanksgiving, and one with Thanksgiving as its middle choice. Cycling is obviously possible in this case, because the group's preferences are not single peaked. See supra text accompanying note 47.

87 T. Jefferson, supra note 23 , at 218 .

88 T. Reed, supra note 23, at 111. Reed goes so far as to say, "In the House of Representatives a motion to fill a blank is treated like any other amendment." Id. at 112 . This is somewhat misleading since in a note the current House rules report: "It is very rare for the House to fill blanks for numbers," implying that the procedure for filling blanks does exist and is used more often for filling blanks without numbers. H.R. Doc. No. 279, 99th Cong., 2d Sess. 219 (1987).

89 A. Sturgis, supra note 23 , at 185.

90 L. Cushing, Law and Practice, supra note 23, at 532.

91 Id.

92 F. Gregg, supra note 23 , at 21. 
Charles Gaines' 1912 revision of Cushing's 1844 Manual suggests beginning with the largest number and then comes closest to fingering the matter in the following passage, which begins with clues suggesting some recognition of the importance of order, but concludes with an example that emphasizes the unambitious assumption of simple (single-peaked) preferences:

The above statement expresses the prevailing American usage, but in the arrangement of numbers there is some variation in practice. The United States Senate, for example, puts first the smallest number and proceeds towards the larger, following the English rule. In the House of Representatives blanks are filled simply by adopting a motion to insert the words desired, and this motion is treated like any other amendment.

Formerly, the arrangement of the series was determined in each case by the nature of the question,- - the theory being that the voting should begin, not at the extreme which, though not offering all that is desired, is so completely within every one's wish that none can vote against it, but rather at that extreme which will be likely to unite the fewest; and from this point the procedure should advance or recede until a number or a time is reached which will unite a majority. But this rather metaphysical problem is not always easy to decide in the press of business; nor will opinions always coincide in regard to it. In point of fact, members commonly vote against all propositions offering either more or less than they desire until the proposition which they favor is reached, after which, if this is rejected, they vote for the proposition which deviates from it least-which is the next in order. Thus nearly the same result is obtained by proceeding in either direction. In an assembly consisting of members A, B, C, D, E, who favor propositions $1,2,3,4,5$, respectively, the result will almost certainly be a compromise upon 3, whether the voting begins with 1 or 5 ; for $\mathrm{C}$ will vote for his preference (3), and the two whose propositions have been rejected will vote for it also, as nearest their wish of what remains open. The essential thing, therefore, is simply to have a definite order understood by all; and the familiar American rule of beginning with the largest number or the longest time is as satisfactory as any. ${ }^{93}$

Finally, Mason's Manual of Legislative Procedure appears to copy Jefferson by suggesting that, when "the greater includes the lesser, the question of the greatest number or longest time should be put first." 
But Mason goes on to suggest that when "the greater does not include the lesser, the smallest number or shortest time should be put first." 94

These authorities illustrate the central point regarding variety in parliamentary law, the voting paradox, and the role of dissatisfaction. Although competing rule systems may have emerged simply in response to a large market, ${ }^{95}$ it is noteworthy that all the rule systems cited above call for a simple majority vote to fill blanks, and all anticipate virtually identical amendments. Indeed, it is easy to imagine attending many formal meetings before a question would arise where it would matter which rules of order guided the assembly. But when it comes to the order in which suggestions are considered to fill blanks, virtually every possible rule is found and there is real variety among rule systems. This striking variety has many possible explanations, but I think it no accident that the process of filling blanks must often run up against the incoherence of majority rule. It is easy to imagine parliamentarians and the drafters of these rules noticing some relationship between outcomes and the voting order when filling blanks, and fiddling with the rule in order to avoid (or hide or make apparent $)^{96}$ this inevitable link. And it is especially easy to imagine disappointed legislators or other voters expressing great dissatisfaction and altering the then-existing scheme. Much as we change speed limits, primary election rules, and product liability rules in response to dissatisfaction-without any real assurance that the innovative rules are truly superior-so, too, codifiers of parliamentary law may have fiddled with the best means of filling blanks.

\section{Dividing Questions}

The rules on division of a question provide a second and perhaps more straightforward illustration of the idea that some variety in parliamentary law is caused by the unavoidable importance of (and dissatisfaction with) procedural rules when it is incoherent to speak of the will of the majority. Imagine that a motion is made by member $A$ "to terminate $W$ 's employment contract, to terminate $X$ 's contract, and to hire $Y$." When preferences are not single peaked, $A$ 's combi-

94 P. Mason, supra note 23, at 288.

95 There is a thin line between product differentiation and innovation, and a wave of new competitors in an industry may reflect either rapid and numerous innovations, or the discovery of a new market followed by imitation, price competition, and minor product differentiation.

96 See supra text accompanying note 71 . 
nation of the three elements may be a strategic device and different results may materialize if $W, X$, and $Y$ 's futures are decided individually or in some other packages. Some voters may most wish to see $W$ depart and may be fairly eager for $Y$ to be hired, but only if $X$ departs as well. Others may be most interested in hiring $Y$, but may regard $X$ 's departure as more important than $W$ 's. And a third goup may least wish to employ $Y$, but may be eager to fire $X$, and even $W$, if $Y$ is not employed. Familiarity with the voting paradox enables one to see quickly that when preferences regarding one matter depend on choices made as to another it is especially easy to imagine non-singlepeaked preferences and, therefore, especially easy for voting paradoxes to arise. ${ }^{97}$ Although some voters' preferences will ultimately be favored by whichever voting procedure is used, it is neither better nor worse in a moral or Condorcet sense to vote on $W, X$, and $Y$ 's futures one at a time, all at once, or in any particular combination.

Cushing's Manual allows a member to move to divide $A$ 's question. ${ }^{98}$ Thus $B$ might move to divide $A$ 's original motion at the three commas so there are three separate motions to consider, one at a time. If $C$ prefers to vote on $X$ 's termination and $Y$ 's employment as a single package, $C$ can move to amend $B$ 's motion accordingly. $A$ is denied the complete power to set the procedure, but if the group has difficulty agreeing on a single plan of division - a real possiblity when the underlying preferences are not single peaked $-A$ 's original package is likely to survive. ${ }^{99}$

97 In all, there are eight different possibilities: (1) fire $W$, fire $X$, hire $Y$; (2) fire $W$, fire $X$, reject $Y$; (3) fire $W$, keep $X$, hire $Y$; (4) fire $W$, $\operatorname{keep} X$, reject $Y$; (5) keep $W$, fire $X$, hire $Y$; (6) keep $W$, fire $X$, reject $Y$; (7) keep $W$, keep $X$, hire $Y$; and (8) keep $W$, keep $X$, reject $Y$. In contrast to previous examples involving numbers or dates, here there is no natural or singlepeaked sequence in which to order the alternatives and there are numerous alternatives so that cycling majorities are quite likely.

98 L. Cushing, Manual, supra note 23, at 54-56.

99 Suppose that $A$ prefers (1) in supra note 97 , that $B$ prefers (3), and $C$ prefers (2). Moreover, suppose each voter will eventually vote for a package that has at least two out of three of his first choice items. $B$ has therefore moved to divide the question because he wants $X$ 's employment continued (and, perhaps, because he prefers two employees for the relevant tasks). $C$ disagrees with $A$ only as to the identity of the new employee and has therefore moved to divide the question differently. $C$ 's amendment to $B$ 's motion will be voted on first and will probably lose because $A$ will probably side with $B$, perhaps because $A$ knows that on an itemby-item basis his preferences are always in the majority. Next, $B$ 's motion to divide $A$ 's original motion would be voted on, but would lose since two voters prefer $A$ 's original motion to $B$ 's division. Thus, $A$ 's motion remains intact and will pass. Note that this is a situation with cycling majorities ( $C$ 's proposal to divide could have defeated $A$ 's in a pairwise 
Cushing notes, however, that the usual rule in American legislatures and other deliberative bodies is to allow division upon the deinand of a single nnember. ${ }^{100}$ The assembly can vote down the request, ${ }^{101}$ but given the likely differences of opinion as to the "best" way to divide $A$ 's original motion, the right to demand a division can be a valuable asset. Cushing notes that:

The rule of the congress of the confederation was, that if the question in debate contained several points, any member might have the same divided; and the rule of the house of representatives of the first congress under the constitution was, that any meinber might call for the division of a question, where the sense would admit of it. ${ }^{102}$

It is possible that under these rules the assembly could not vote down the single member's request.

The 1876 edition of Robert's Rules lists the division of the question as a type of amendment, and by implication, therefore, not the right of a single member. ${ }^{103}$ Later versions, in accord with virtually all competing guides, ${ }^{104}$ call for a vote on division but, interestingly enough, give any unember the absolute right to divide the question when the pending inotion's various resolutions are "dealmg with different subjects." 105 I think this last rule has more to do with the deep meaning of majority rule than with voting paradoxes, but in some

comparison, completing the cycle) and that the order the proposals were voted on determined the outcome. See supra note 43 and accompanying text.

100 L. Cushing, Law and Practice, supra note 23, at 528-29. Cushing notes that most state legislatures have a special rule allowing division on a single member's demand unless overruled by the chair or majority vote. Id. However, Cushing stresses that this is not the common law rule and reports that the issue was settled when in "the year 1770, a question arose in the house of commons, whether an individual member had not a right to have a complicated motion divided into its several parts, and a question put separately on each, on his mere demand, and without any motion or vote for that purpose. ... This question was debated at length, and was decided in the negative . . . ." Id. at 1005-06; see also L. Cushing, Manual, supra note 23 , at 55-56 (usual amendment process used for question division).

101 See supra note 100 .

102 L. Cushing, Law and Practice, supra note 23, at 530.

103 H. Robert, Pocket Manual, supra note 1, at 154.

104 See, e.g., P. Mason, supra note 23, at 227; A. Sturgis, supra note 23, at 227.

$105 \mathrm{H}$. Robert, supra note 1, at 230-32 (Makes a distinction between a motion "relating to a single subject [containing] several parts, each of which is capable of standing as a complete proposition if the others are removed," and a motion containing "a series of independent resolutions dealing with different subjects." The latter may be divided on demand while the former may only be divided if a majority approves.). 
sense the two are inseparable. ${ }^{106}$ In any event, there is obvious variety where voting paradoxes are likely.

\section{Other Variety}

There is a fair amount of variety among parliamentary codes which has little to do with the voting paradox. A few guides permit a "motion to substitute" and an amendment to that motion so an assembly can face simultaneously up to five alternatives rather than three. ${ }^{107}$ The authorities also differ as to how to "close nomina-

106 We sometimes seek majority approval on many issues at once, as in a presidential election, where each candidate stresses an approach rather than a single issue, but for the most part our vision of majority rule is individual issues being considered by citizens, legislators, or members of some other group. To the extent, however, that all things are interrelated, it is often puzzling (and frustrating) how little the "majority" has to say about larger issues. Thus, legislatures vote on many individual bills, but rarely is there a real, potentially constraining vote on the overall level of expenditures, air quality, or other cumulative matters. Indeed, many people take the very idea of decisionmaking to mean the ability to express an opinion on a given subject rather than the power to choose among enormous and complex alternative packages with hundreds of components. As a result, the order in which decisions are made, as distinguished from the order in which proposals concerning a single decision are presented, can also matter a great deal. Law firms and faculties hiring new colleagues, for example, generally consider applicants one at a time and there are often thought to be advantages or disadvantages to consideration early in the "season."

It is possible or even likely, of course, that the division of proposals has less to do with any deep meaning of majority rule than it does with the practical concern that packages of proposals can be manipulated by strategic, or even corrupt, insiders to force voters into choosing among alternatives which uniformly contain proposals serving the insiders', or agenda-setter's, interests.

It is noteworthy that many state constitutions require that no bill contain more than one subject. See, e.g., Ala. Const. art. II, §13 ("Every bill shall be confined to one subject, unless it is an appropriation bill or one [changing] existing laws."); Ariz. Const. art. IV, pt. 2, § 13 ("Every Act shall embrace but one subject."); Cal. Const. art. IV, §9 ("A statute shall embrace but one subject."). This requirement may give the executive more power, because it is the equivalent of a line-item veto, and may secure independent judgments on each subject before the deliberative assembly.

107 As noted earlier, the United States House of Representatives and a few authorities based on the House rules treat a substitute amendment differently and allow its introduction along with ordinary primary and secondary amendments. An amendment to the substitute amendment is also permitted. See supra note 80; H.R. Doc. No. 279, 99th Cong., 2d Sess. 565 (1987); J. Tilson, supra note 23 , at 74 .

However, most authorities treat a substitute amendment as any other amendment, see, e.g., H. Robert, supra note 1 , at 128-29; Z. Moore \& J. Moore, supra note 23 , at $11-12$, and thus 
tions" 108 and which motions require "seconds." 109 It is possible that innovations in these areas also followed dissatisfaction. Confusion about the propriety of moving a fourth alternative after pending amendments were defeated may have encouraged the development of the motion to substitute. Likewise the motion to substitute may have fallen into disfavor because of the confusion engendered by considering so many alternatives at once. Similarly, with regard to the making and closing of nominations, dissatisfaction with a powerful chair or with additional nominations which weakened a voting bloc may have stimulated changes in the rules. ${ }^{110}$ It is particularly easy to see

limit the number of pending proposals to three (the main motion, the primary amendment, and the secondary amendment).

Finally, for a rule allowing three proposals to be pending (like Robert's Rules) but requiring that the substitute be compared with the main motion in the final vote (like the House Rules), see G. Demeter, supra note 23 , at 79-82.

108 Robert distinguishes between elections in small bodies and large assemblies. In the former, the chairman should ask for nominations until no more are offered, and then declare that nominations are closed, whereas in the latter a formal motion to close nominations, requiring a two-thirds majority, is sometimes needed. H. Robert, supra note 1, at 242-43. Sturgis, however, requires only a majority vote to close nominations. Sturgis goes on to say that the motion is unnecessary since members are not limited to voting for nominated candidates when voting by ballot. A. Sturgis, supra note 23, at 73-74. Keesey includes the motion to close nominations in his chapter dealing with "Motions Not Recommended." $\mathrm{R}$. Keesey, supra note 23 , at $83,90$.

109 The basic idea behind requiring seconds for motions is that the deliberative assembly should not waste time on issues of concern to only one member. Different authorities, however, have different views about when to require seconds. Compare $H$. Robert, supra note 1 , at 28-30, $42-43$ (requiring seconds for most motions with about a dozen exceptions) with $\mathrm{R}$. Keesey, supra note 23, at 31 (declaring seconds a waste of time and that no motions need be seconded) and with L. Cushing, Manual, supra note 23, at 37 (favoring seconding all main motions except for routine business) and with $\mathrm{H}$. Shattuck, supra note 23 at 58-59 (noting that chair decides if a motion needs a second but advising the chair not to be too strict in requiring seconds).

A related example of variety is many parliaments' rules that require more than one member to introduce, or initiate, a bill or amendment. In Austria, eight are required; in Syria, 10; in Poland, 15; in the Republic of Korea, 20; in Romania, 35; and in Spain, 50. V. Herman \& F. Mendel, Parliaments of the World 599-600 (1976).

110 Arguments can be made both for and against any procedure to close nominations. Those who tend to discount strategic behavior might say that it is unfair to close nominations as long as anyone remains interested in making one. Those who have observed strategic operators in action may counter this by arguing that the only nominations prevented by a successful motion to close nominations are those designed to fragment coalitions. See supra note 81 . Allowing nominations to be closed by a two-thirds vote may simply be a way to prevent wasting time on candidates supported by only one or two members. It is easy to imagine changes in the rule as parliamentarians sense unfairness, manipulation, or unnecessary delay. 
how the usually trivial requirement of a "second" could fall in and out of favor. ${ }^{111}$

There is also variety in the use of secret ballots in decisionmaking. Secrecy was used in ancient jury trials but now is regarded as wise and even sacred only in general elections, but not in juries, whose members may be publicly polled, and not normally in deliberative assemblies. ${ }^{112}$ Secrecy encourages the revelation of true preferences, because it is difficult to threaten or bribe voters when their votes are secret, and suppresses dissatisfaction, because open voting is likely to reveal more information about (cycling) preferences. To the extent, however, that transaction costs prohibit the recording of preferences as to all alternatives, open voting may encourage the emergence of Condorcet winners because members can learn about each other's preferences and are able to introduce fresh alternatives. Moreover, secret ballots encourage corruption when unanimity is required; a jury member whose vote for acquittal has been purchased will have a greater fear of an investigation (into the possibility of an illicit arrangement with the defendant) if the lone vote for acquittal is public than if it were secret. I think it is no accident that juries in Socrates' time, which needed only a majority decision, voted secretly, while the modern preference for unanimous verdicts for criminal convictions is correlated with the polling of jurors. Apart from this possible connection, the variety about secrecy in voting can be explained by the presence of both advantages and disadvantages to secrecy.

The interaction between collective choice problems and parliamentary rules is not limited to two or three procedures. The interaction is

111 A group with several difficult or overenthusiastic members may very well want a strictly enforced second requirement for all motions to prevent the entire assembly from having to vote on every idiosyncratic motion backed by one member. But if a group finds that almost every proposal has the support of at least a few members and few proposals fail to be seconded, or few are long winded, then the requirement of a second will seem trivial and counterproductive- a timewaster instead of a timesaver. In turn, once the requirement of a second is done away with, the appearance of one idiosyncratic member could make the other members yearn for the good old days when motions required seconds.

112 See, e.g., H. Robert, supra note I, at 346-48. Generally, nonsecret methods of voting are used, such as a show of hands, a voice vote, or rising to be counted, although the "bylaws of an organization may prescribe that the vote be by ballot in certain cases, as in the election of officers and in admission to membership." Id. at 347-48. A vote by secret ballot may also be used on any issue where a majority votes to use a secret ballot, and after the vote "no motion is in order that would force disclosure of a member's vote or views on the matter." Id. at 348. See also Larsen, supra note 13, at 170 (ancient origins and use of secret voting). 
also apparent, for instance, in the rules dealing with tertiary amendments and with the question of revisiting issues that have already been voted down as parts of other motions. ${ }^{13}$ But one last example of variety that merits special attention is the tie-breaking or tie-making power of the chair. Groups probably wish the chair both to be ready to break ties and to have power equal to that possessed by any other voting member. Unfortunately, these simple conditions may be mutually unattainable. If the chair has only a "deliberative" vote, like any other member, but no "casting" or tie-breaking vote, ties will often materialize and will defeat the motion because of the ancient rule that a motion needs a majority to pass. The motion's defeat by way of a tie vote is unattractive, in part, because the defeat hinges on a procedural point (that the chair might control); a conversely framed motion might also have failed. Thus, imagine that a group is deciding whether or not to fire $X$. Member $B$ might move to retain $X$, but member $C$ might move to discharge $X$. If the group is evenly divided, $X$ 's future will depend on which motion is made. ${ }^{114}$ And if a chair only breaks ties, or casts, the chair is often less powerful than other members. A group may favor a motion five votes to four, even though the chair would have voted against the motion and the tie vote would have defeated it. Finally, the chair may be given both a deliberative and a casting vote, although it seems rather obvious that this will sometimes make the chair more powerful than any other member. If groups wish to avoid ties, they must give the chair either a deliberative and a casting vote, or a casting vote alone. The first alternative gives the chair more power than is desirable and the second gives less, so practice may vary among both these options and that of simply giving the chair only a deliberative vote and suffering through

113 The standard rule regarding reconsideration of a proposal that has been voted down is that the proposal may be reconsidered once but not twice. See supra note 28; see also, e.g., H. Robert, supra note 1 , at 270 (providing for a unanimous consent exception to the rule against reconsidering something twice). This rule interacts with the voting paradox in two ways: First, in the presence of cycling majorities, the limit on repeated reconsideration prevents indefinite cycling; and, second, if there is a Condorcet winner that has been excluded, the assembly can conceivably reconsider its rejection of this alternative before adopting a "wrong" choice. Note that the rejection of a Condorcet winner will occur only under sincere voting, since sophisticated voters will presumably consider the ultimate outcome and vote in ways that produce the Condorcet winner. See infra note 136 on sophisticated voting and the guaranteed selection of Condorcet winners. See infra notes 133-34 and accompanying text for discussion of how certain voting procedures can result in missing a Condorcet choice.

${ }^{114} X$ will, of course, prefer that $C$ 's motion be voted on, for it will "fail" by a tie vote. 
some ties. I will return to this topic in Part III, but meanwhile it is useful simply to note that variety in the chair's voting power is easy to understand given the set of less-than-ideal alternatives.

Indeed, under some rnles-especially if the chair is not a member of the body, like the Vice President in the United States Senate-the chair has only a casting, or tie-breaking, vote. And under othersespecially common in committees-the chair has a deliberative and a casting vote. ${ }^{115}$ The standard rule, however, ${ }^{116}$ gives the chair only a deliberative vote, thus creating some unresolved ties and making the form of the original motion matter. But in practice, most chairs appear to refrain from exercising their deliberative votes even, or especially, when to do so would create, rather than break, ties. ${ }^{117}$ Motions can thus pass by what might otherwise have been a tie vote, and the net effect is simply to suppress the fact that the form of the original motion matters. Such suppression will continue to be a familiar evolutionary theme in parliamentary law.

The variety among these rules about deliberative and casting votes appears all the more remarkable in light of the ambiguity even in Aeschylus' description of Athena's casting vote; it is possible that even in ancient Athens citizens were uncertain which rule did or should prevail. ${ }^{118}$ I believe this intriguing example of variety has a definite relationship to the problem of collective choice, but its explication must be deferred to the discussion of plurality voting in Part III.

115 See Banks, The Chair's Casting Vote: Some Inconsistencies and Problems, 16 W. Ont. L. Rev. 197, 203 (1977) (noting that during the committee stage in the Canadian House of Commons and United Kingdom House of Commons the chair gets both a deliberative and a casting vote).

116 See, e.g., H. Robert, supra note 1, at 343-44 (Presiding officer may vote as any other member when his vote will affect the result. But "[t] $]$ he chair cannot vote twice, once as a member, then again in his capacity as presiding officer-first to make a tie, and then to cast the deciding vote."). For a brief discussion of the origin and reason behind the American practice of allowing the chair to vote either to make a tie or to break a tie, see Banks, supra note 115 , at 208-09.

117 When secret ballots are cast the chair may as well vote along with everyone else and, indeed, this procedure allows the chair's own vote to be secret because under the standard rule there is not an additional tie-breaking vote. See, e.g., H. Robert, supra note 1 , at 343,349 (chair may vote as any other member if the vote is by secret ballot).

I18 See 2 G. Thompson, supra note 8, at 228 (Some scholars believe that the jurors were tied before Athena voted, thus she had a casting vote, while others believe that the jurors became tied only after Athena voted, thus she had a deliberative vote.); see also R. Fagles, Aeschylus: The Oresteia 335-36 (1975) (vexing question of whether jurors voted 6-5 with Athena as tiemaker, or voted 5-5 with Athena as tiebreaker). 


\section{VOTING Formats}

\section{A. The Uniformity of the Motion-and-Amendment Process in Parliamentary Law}

As implied earlier, the most striking uniformity in parliamentary law is the universal use of the "motion-and-amendment" format for making decisions. ${ }^{119}$ The main motion (and there can be only one pending at any time) may be amended in various ways, but amendments are voted on one at a time until finally the main motion, with or without amendments, is ready for consideration. The format is striking both because it is the centerpiece of virtually all American parliamentary rule systems and because it is so uncommon outside of meeting halls. Indeed, the only report of its use outside of deliberative assemblies is from ancient times. ${ }^{120}$ In contrast, plurality voting among multiple options, with or without subsequent runoffs, is common in general elections and elsewhere, but is never used inside deliberative assemblies. ${ }^{121}$ Political parties may, of course, so severely

119 See supra note 39.

120 In the Homeric epics, audiences sometimes appear to use a "forward" motion-andamendment procedure to choose between the views of two leaders. "Even when the assembly did decide between two rival proposals, there was no formal vote or counting of votes, but the last proposal to be presented and applauded was considered adopted." Larsen, supra note 13, at 166. This ancient format is striking because, although it involved head-on competition like the modern motion-and-amendment process, the last proposal presented was the last to be evaluated with applause or silent disapproval. I have not found an Homeric description of such a choice among more than two alternatives, but it is possible that such a forward motionand-amendment procedure was used generally.

121 With rare exception, the only time plurality voting is used in parliamentary law is for the election of officers. Though Robert is careful even in this context never to allow selection by relative majority, he allows preferential voting and repeat balloting with elimination of the candidate securing the fewest votes, if such procedures are in the bylaws. H. Robert, supra note 1 , at $357-60,369-71$.

In this Article, I use plurality voting as a label which covers all methods of voting with at least one round of simultaneous voting among multiple (three or more) candidates. This includes simple plurality voting, preferential voting, plurality voting with a runoff, most proportional representation systems, and other less common election types. In simple plurality voting, the winner is the recipient of a relative majority of the votes or, when there are $n$ seats to be filled, the $n$ candidates with the most votes. This is the most common way of electing public officials in the United States. See supra note 4.

Preferential voting, a concept which predates Condorcet in the work of Borda, see supra notes 43-45 and accompanying text, calls for the voters to rank the candidates. In most forms of preferential voting, only one round of voting takes place, but there can be several rounds of calculations, as the voters' preferences are taken into account. See infra note 162 for an example of preferential voting, the "alternative vote." See also Wright, Australian Experience with Majority-Preferential and Quota-Preferential Systems, in Electoral Laws and Their 
limit alternatives in both general elections and deliberative assemblies as to make plurality voting the equivalent of motion-and-amendment voting. Nevertheless plurality voting is important in political primaries, local school board elections, and other nondeliberative settings. ${ }^{122}$ Within deliberative assemblies, the most familiar alternative to motion-and-amendment decisionmaking is succession voting, under which the first alternative is approved or excluded, followed by the second alternative, and so forth. ${ }^{123}$ But the very fact that its use in

Political Consequences 124 (B. Grofman \& A. Lijphart eds. 1986) [hereinafter B. Grofman \& A. Lijphart] (describing development and consequences of preferential voting in Australia).

In plurality voting with a runoff, also known as double-ballot voting, if no candidate holds an absolute majority after the first vote, a second vote, "the runoff," is held. The field is usually narrowed for this second ballot either to the top two candidates or to all candidates receiving more than a threshold percentage of the first ballot vote. Currently France uses such a double-ballot system for its parliamentary elections, with candidates who have received over $12.5 \%$ of the vote in the first round allowed onto the second ballot. In this second ballot, a relative majority wins, so that there is no third round. See Fisichella, The Double-Ballot System as a Weapon Against Anti-System Parties, in Choosing an Electoral System: Issues and Alternatives 181 (A. Lijphart \& B. Grofman eds. 1984) [hereinafter A. Lijphart \& B. Grofman]. B. Grofman \& A. Lijphart, supra, at 183-254, also contains discussions of many different aspects of plurality voting.

122 To the extent that political parties limit the number of alternatives under consideration to two, the comparison among methods of decisionmaking is simply uninteresting. It has previously been noted that political parties may play precisely this role and suppress collective choice problems. See supra note 52. Put somewhat differently, in some settings it is surely the stability of the governing coalition, the value of incumbency, or a similar variable that is most important in understanding the decisionmaking process. In these settings plurality and motion-and-amendment voting may be close substitutes.

It is interesting, but not terribly helpful, to note that plurality voting often concerns a choice among individuals while motion-and-amendment voting often involves decisionmaking with regard to issues. Plurality voting avoids head-on comparisons in which losing may be more embarrassing when individuals are concerned. Nevertheless, plurality voting with runoffs among individuals is not uncommon. Although humiliation and hurt feelings may be greater when one loses a head-on, rather than a plurality, comparison, issues so often become associated with personalities that there may be just as much emotional scarring when issues are voted on as when individuals are compared.

123 There are at least six procedures commonly used in committees: the succession method of voting, the motion-and-amendment method, the plurality procedure, the "elimination" procedure, the "Dodgson" procedure, and the "Alternative Vote" procedure. See R. Farquharson, supra note 43, at 61-63. I have found no parliamentary authority or practice which suggests using any of the last four of these methods on a regular basis. The lone exception is R. Keesey, supra note 23 , at $44-45$, who, in the context of filling blanks, allows simultaneous (as opposed to succession) voting with the option receiving the most votes to win. This is the only example I have found of simple plurality voting in the rules of deliberative assemblies. 
parliamentary procedure is limited to filling blanks highlights the dominant position occupied by the motion-and-amendment process.

Moreover, the uniformity of the motion-and-amendment process in parliamentary law is an apparent blow to the dissatisfaction hypothesis. Dissatisfaction with motion-and-amendment voting seemingly should have occurred when the conditions for the voting paradox were present, and this dissatisfaction should have caused innovators to suggest succession or plurality voting. The blow to the dissatisfaction hypothesis, if it is that, is relatively small because many coalitions dissatisfied with the results of the motion-and-amendment process would not have fared better under succession voting. Imagine, for example, that $A, B$, and $C$ rank three alternatives 123,231 , and 312 respectively, and that $A$ moves the passage of $1, B$ proposes an amendment which amounts to 2 , and $C$ 's secondary amendment is 3 . As noted earlier, $C$ 's proposal will lose to $B$ 's, which will then lose to 1 . $B$ and $C$ will be dissatisfied because they prefer 3 to 1 , but under succession voting, with the same order of recognition and with voting proceeding from the first proposal to the last, only $A$ would vote for 1 , and 2 would have then emerged with $A$ and $B$ voting for it. $B$ and $C$ may sense that 3 would win if the proposals had been considered in a different order, but it is not the case that a switch to succession voting would have yielded 3 rather than $1 .^{124}$ Dissatisfaction might therefore cause innovation as to the order of recognizing speakers, but it is hard to see how it would stimulate evolution toward succession voting.

There are, however, examples involving more than three voters in which a switch to succession voting would appease dissatisfied blocs:

\begin{tabular}{lccccc} 
Voter: & $A$ & $B$ & $C$ & $D$ & $E$ \\
\hline Most preferred & 1 & 2 & 3 & 4 & 5 \\
& 2 & 3 & 1 & 5 & 4 \\
& 3 & 5 & 4 & 3 & 2 \\
Least favored & 4 & 4 & 2 & 1 & 1 \\
& 5 & 1 & 5 & 2 & 3
\end{tabular}

\footnotetext{
124 Alternative 3 would win under the motion-and-amendment process with sophisticated voting, because $B$ can be shown that 2 is unattainable and that voting down $C$ 's amendment will result in 1 , the worst outcome from $B$ 's perspective. But sophisticated succession voting yields 1 rather than 2, because $A$ can explain to $C$ that, unless $C$ votes for 1,2 will emerge in the next step of the succession process. Indeed, the dissatisfied majority under sophisticated succession voting ( $B$ and $C$, who prefer 3 over 1 ) might stimulate evolution back to motionand-amendment voting because when it is sophisticated it does generate 3 .
} 
In this example there is cycling, and no Condorcet winner, because 1 defeats 2, 2 defeats 3,3 defeats 4,4 defeats 5 , and 5 defeats 1 . Under succession votimg, if proposals suggestimg $1,2,3,4$, and 5 are recognized in that order, only $A$ will vote for 1 , and only $A$ and $B$ will vote for 2 , but 3 will wim, because $A, B$, and $C$ most prefer 3 after 1 and 2 are elimmated. Under parliamentary law's motion-and-amendment process, with the same order of recognition, a likely scenario is as follows: 1 is moved; 2 is proposed as an amendment; 3 is mtroduced as a secondary amendment; 3 is voted upon (and thus competes with 2) with the victor tested against 1; 4 is then proposed as an amendment, with 5 as a secondary amendment; ${ }^{125} 5$ is tested against 4 , with the victor tested agamst whichever emerges from the 1-2-3 motionand-amendment process. Given the above preferences, $A, B$, and $E$ will vote for 2 over 3 , and 1 will then defeat 2 because of $A, C$, and $D$ 's support. Next, $A, C$, and $D$ will vote for 4 over 5 , and, finally, 4 will defeat 1 based on $B, D$, and $E$ 's votes. $A, B$, and $C$ will be dissatisfied because they form a majority that prefers 3 to 4 . Moreover, they will feel wronged that succession voting had not been adopted because, as seen earlier, it would have yielded 3 with the same preferences and order of recognition. ${ }^{126}$

In sum, the uniformity of the motion-and-amendment process im parliamentary law is quite striking because the alternatives of succes-

125 Note that this order would be slightly different if amendments in the form of substitutes were allowed. See supra note 107.

126 This example assumes sincere voting. If sophisticated voting is assumed, then the results differ. The succession winner would probably be 1 . $E$ would realize that he preferred 2 over 3 and switch his second vote to one in favor of 2 , giving 2 a total of three votes. However, since $C$ and $D$ know that $E$ will vote in this way, they will preemptively vote in favor of 1 (along with $A$ ) in the first vote, since they prefer 1 to 2 . Hence, 1 will be adopted in the first vote.

Under the motion-and-amendment procedure with sophisticated voting, 3 will probably win. Sophisticated voters would realize that if 3 is eliminated in the first round where 2 competes against 3, then 4 will win. (Note that if 3 is eliminated, 4 is a Condorcet winner among the remaining choices since 4 defeats 1,2 , and 5 ). They will also realize that if 2 is eliminated in that very first vote, 3 will win since 3 is then a Condorcet winner among the remaining alternatives ( 3 defeats 1,4 , and 5 ). Thus, the first vote between 2 and 3 is really the critical vote between 4 and 3 . Since a majority prefers 3 to 4 , a sophisticated majority will vote for 3 in the first round. In this series of sophisticated votes, 3 will defeat 2,3 will then defeat 1,4 will defeat 5 , and, finally, 3 will defeat 4 . Once 3 is adopted, $A, B$, and $E$ will be dissatisfied because they prefer 2 over 3 . However, in a sense, it should be mild dissatisfaction because $A$ and $B$ should realize that though they prefer 2 to 3,3 is preferable to the other realistic alternative (namely 4). 
sion and, especially, plurality ${ }^{127}$ processes are available and are used elsewhere, and because the dissatisfaction thesis suggests that in settings with numerous voters and issues there might have been evolution toward these alternative voting procedures. An inability to explain this uniformity would not destroy the dissatisfaction idea, but would weaken it. ${ }^{128}$

A weak explanation for the regular use of the motion-and-amendment process inside, and only inside, dehberative assemblies is that the moral, practical, and mythical underpinnings of majority decisionmaking are served by a process in which the final decision is ratified not by a mere plurality, or relative majority, but by a "real" (fiftyone percent) majority. Although this explanation rationalizes the absence of plurality voting from parliamentary law it raises the questions of why plurality decisionmaking is popular in general elections, why succession voting is used only sparingly in parliamentary systems, why plurality voting with a runoff (which also produces a "majority" winner in the final round) is not found in parliamentary law, and why parliamentary law does not simply test every alternative in "round-robin" fashion in order to be sure of a fifty-one percent, majoritarian winner. ${ }^{129}$

127 Similarly, one might have expected evolution from the motion-and-amendment process to plurality voting. For example, with the preferences set out in the text preceding note 73,1 or 10 could emerge under the motion-and-amendment process. See supra note 77. A majority would then be dissatisfied, however, for 20 is preferred to both 1 and 10 . This majority would have had its way under sincere plurality voting. Of course, plurality voting eventually would lead to dissatisfaction as well.

128 A "sophisticated dissatisfaction" claim, see supra note 67 , that evolution occurs only when farsighted, disappointed majorities see another procedure that would not in turn lead to dissatisfaction, would fare poorly in explaining the variety discussed in Section C of Part II.

129 The scope of such a comparative inquiry obviously can be widened to include nonpolitical, nondeliberative (that is, without discussion), competitive scoring systems. In Olympic figure skating, diving, and gymnastics, for instance, the scoring or voting method makes use of a number of judges, or voters, who give each performer a score on a 10-point scale. The winner is the competitor who receives the most points (adjusted in some cases for degree of difficulty). Conceivably, this same method of voting could be used in a deliberative assembly to choose among several alternatives. Each alternative would be given a numerical score by each member, and totals might be taken after extremely high and low scores were discarded (as in some sports). One explanation of why this method is not used may be that sophisticated voting would turn such a system into a pure plurality system since each member could act as a terribly partial judge in the Olympics, giving high scores to the favored alternative and giving especially low scores to that alternative's major competitors. As discussed in the text presently, this can easily lead to the elimination of a Condorcet winner. However, if sophisticated voting.is practiced by all voters in this context, the members, or 
Some of these questions can be parried by reasoning that the use of plurality voting in general elections serves to minimize "transaction" costs, because only one or two rounds of voting are required, while motion-and-amendment voting is used in deliberative assemblies where a modest increase in transaction costs is acceptable in return for a fifty-one percent majority result, but where the far greater transaction costs associated with succession or round-robin voting are still unacceptable. ${ }^{130}$ Here, as in many other areas of law, the transaction costs argument has the flavor of an ex post rationalization. If succession voting were uniformly used inside deliberative assemblies, it would be easy to argue that this form of decisionmaking lowers transaction costs and that these costs are important even inside deliberative assemblies. Indeed, if general elections more closely resembled motion-and-amendment decisionmaking, so that an incumbent competed only in head-on competition against the single survivor of intraand inter-party primaries, one might again argue that transaction costs were minimized. In short, transaction cost considerations may lead one to expect that round-robin voting will not often be used in deliberative assemblies or in general elections, but otherwise transaction costs seem to be only a noteworthy variable rather than the key to explaining the variety in decisionmaking processes.

One might seek to explain a good deal of parliamentary law, and especially deliberative bodies' uniform adoption of the motion-andamendment process rather than more straightforward plurality voting, with the idea that well-managed (nonmajoritarian) interest groups have worked to install complex rules because such rules favor

judges, will realize the danger of an unpopular choice emerging and will vote strategically to assure the adoption of a Condorcet winner. See infra note 136 on how strategic, sophisticated voting is likely to lead to the adoption of a Condorcet winner.

For a discussion of the effects of different voting methods and for an interesting example of how a group of scientists decided on the path (from 32 possible alternatives) for an extended space probe, through the use of ordinal rankings, cardinal utilities, multiplicative cardinal utilities, and ordinal head-to-head comparisons, see W. Riker, supra note 43, at 21-40 (citing Dyer \& Miles, An Actual Implieation of Collective Choice Theory to the Selection of Trajectories for the Mariner Jupiter/Saturn 1977 Project, 24 Operations Research 220-44 (1976)).

130 In general elections many more voters must be polled, so that the absolute level of transaction costs is far greater than in deliberative assemblies. To the extent, however, that voting is a form of enjoyable consumption (which might explain why any rational individual votes in the first place), multiple rounds of voting may be better rather than worse. See A. Sen, supra note 40, at 195 ("It may, of course, be that people just enjoy voting."). 
cohesive groups which can invest resources in manipulating complexities. Complexity can certainly be to the advantage of a minority that would not get its way with simple votes. But this theory has limited explanatory power. First, parliamentary law is replete with rules that seem quite "anti-complexity" in nature, such as the rule limiting the number of pending amendments to a motion. ${ }^{131}$ Second, the parliamentary rules used in a great variety of clubs, associations, legislatures, and voluntary organizations are remarkably similar, and this uniformity seems at odds with the idea that interest groups' efforts have largely shaped the rules of decisionmaking.

The most convincing explanation for the uniformity of the motionand-amendment process in parliamentary law returns us, instead, to the Condorcet criterion. ${ }^{132}$ The motion-and-amendment procedure is one of the very few decisionmaking strategies that guarantees the emergence of a Condorcet winner. Put differently, if one shifts the focus from the voting paradox and unavoidable dissatisfaction to avoidable dissatisfaction in situations where one alternative is preferred by some majority to any other alternative, the prevalence of the motion-and-amendment process in parliamentary law is neatly understood because it is a process that promises to find this clear winner.

Although a Condorcet winner is preferred to any competitor, it can easily be rejected in the early rounds of sincere succession voting, because two voting blocs can form a coalition that defeats the Condorcet winner. ${ }^{133}$ Similarly, a Condorcet winner can be eliminated in plurality voting, with or without subsequent run-offs, because firstplace votes for competitors can combine once again to exclude the Condorcet winner. In contrast, a Condorcet choice will always

131 For an explanation of the process surrounding a "motion to substitute" and the maximum number of alternatives under consideration, see supra note 107.

132 See supra notes $55 \& 68$.

133 Consider a situation with three voters, $A, B$, and $C$, voting on three alternatives, 1,2 , and 3. If the voters, $A, B$, and $C$ have preference orders of 123,213 , and 312 , respectively, then 1 is the Condorcet choice, since some majority of voters prefers 1 to 2 and also 1 to 3 . However, if the method of voting is succession voting and 1 is voted on first, it will be defeated by $B$ and $C$ 's votes, assuming sincere voting. Thus, the Condorcet winner can be defeated.

Note that one can hardly scoff at the likelihood of seemingly naive, sincere voting. Elected representatives may be more concerned with the positions they appear to take than with the optimal strategy for reaching the favored end result. For several examples of such intentionally sincere voting, see Denzau, Riker \& Shepsle, Farquharson and Fenno: Sophisticated Voting and Homestyle, 79 Am. Pol. Sci. Rev. 1117 (1985) (legislative behavior and legislative results both matter). 
emerge out of the motion-and-amendment process because every alternative has a chance until it loses in one head-on comparison. ${ }^{134}$ Consider, for example, the following noncycling preferences:

\begin{tabular}{ccccc}
$A$ & $B$ & $C$ & $D$ & $E$ \\
\hline 1 & 2 & 2 & 3 & 3 \\
3 & 1 & 1 & 1 & 1 \\
2 & 3 & 3 & 2 & 2
\end{tabular}

Alternative 1 is the Condorcet winner, but it would be excluded in a plurality vote ${ }^{135}$ and would obviously lose if presented first in succession voting. ${ }^{136}$ But 1 cannot lose under the motion-and-amendment process, even in the relatively disadvantageous tertiary amendment position, because 1 defeats both 3 and 2 in head-on competitions. I do not mean to imply that plurality or succession voting always or often misses a Condorcet choice; the point is that these formats may miss the Condorcet alternative while the motion-and-amendment process will not. To be sure, if there is no Condorcet alternative, then the

134 Long after developing this line of argument, I finally caught up with some works that make this point. See, e.g., Merrill, A Comparison of Efficiency of Multicandidate Electoral Systems, 28 Am. J. Pol. Sci. 23 (1984) (simulating elections with various numbers of candidates in order to estimate how likely various procedures are to yield Condorcet winners); Miller, Graph-Theoretical Approaches to the Theory of Voting, 21 Am. J. Pol. Sci. 769, 781 (1977); Miller, A New Solution Set for Tournaments and Majority Voting: Further GraphTheoretical Approaches to the Theory of Voting, 24 Am. J. Pol. Sci. 68 (1980). W. Riker, supra note 43 , at $69-72$, notes the Condorcet quality of the motion-and-amendment process with three alternatives, but insists that it is an unattractive process for four or more alternatives. Riker's example, however, does not in fact demonstrate the suppression of a Condorcet winner. See also H. Nurmi, supra note 45, at 40-61 (incorporating Miller's work and reviewing quite generally the capacity of various voting procedures to identify Condorcet winners).

135 Alternative 3 would win in a runoff between 2 and 3, unless some tie-breaking scheme not employing $A$ favored 2 . And 1 would not win under any plurality system.

136 Again note that the text assumes sincere voting. With sophisticated voting by all participants, a Condorcet winner is likely to emerge regardless of the voting method. See, e.g., Denzau, Riker \& Shepsle, supra note 133, at 1123 ("Sophisticated voting by all voters yields the Condorcet winner whenever one exists."). Voters will act so as to assure the best end result, and an alternative can be the best for a majority of voters only if there is no other alternative which the majority prefers. In discussing sophisticated, or strategic, voting, I assume all voters have perfect information about all the other voters' preferences, that each voter wants to secure the selection of the highest possible alternative in his preference order, and that the voters do not trust each other (that is they cannot make binding deals about future votes). In contrast, Riker's definition of strategic voting includes trust in vote trading and the (likely) possibility that only some voters will vote strategically, and he concludes that there is "no way to evaluate the consequences of strategic voting." W. Riker, supra note 43 , at 156-57. 
motion-and-amendment process generates dissatisfaction. That this dissatisfaction has not caused a move away from motion-and-amendment voting as the foundation of parliamentary law suggests that the ability of the motion-and-amendment process to deliver Condorcet winners when they exist was somehow intuitively recognized and protected from reform.

It is tempting to conclude that the uniformity of the motion-andamendment process in parliamentary law is now neatly explained because it alone guarantees the emergence of a Condorcet winner, and therefore, evolution away from the motion-and-amendment process would create avoidable dissatisfaction. But I have not established that the motion-and-amendment process is the only means of guaranteeing the emergence of the Condorcet winner and, indeed, it is obvious that a round-robin procedure which pairs all possible combinations would not only expose a Condorcet choice but also would keep the order of recognition from determining the outcome. The obvious explanation, however, for the relegation of round-robins to contexts such as athletic tournaments ${ }^{137}$ is that changing from motion-and-amendment to round-robin voting, in addition to increasing transaction costs, threat-

137 The method of determining a winner or a set of winners in athletic competitions is obviously closely related to the voting problems discussed in this Article. Moreover, there is significant variety among these methods, as the "competition paradox" suggests; it is not unusual for $A$ to defeat $B$, in a singles match of tennis for example, for $B$ then to defeat $C$, and for $C$ to defeat $A$. How should winners be determined when intransitivity is common? If there is a somewhat objective measuring stick, such as elapsed time in a footrace, it is common to use the objective measure or some combination of it and the order of finish. But when there is no such measure, the choices look quite familiar. Single elimination tournaments, such as most tennis tournaments, promise not to miss a Condorcet winner if any exists. If none exists, however, then $A$, after defeating three of sixteen entrants, may defeat $P$, who began in the other "bracket" and defeated three other players, in the final round of a tournament, even though at least one of $P$ 's earlier opponents could have defeated $A$. But there is no obvious "dissatisfaction," because there is no evidence of such intransitivity and because there is obviously no undefeated player other than $A$.

It is interesting to observe that in professional bowling a version of motion-and-amendment competition is used. If competitors $A, B, C, D$, and $E$ finish in that order in the first round of (simultaneous) competition, then $E$ bowls against $D$, with the winner pitted against $C$ in the third round, and so forth. $A$ need only "defend" his first-round lead once. Somewhat similarly, in Wimbledon and Davis Cup tennis tournaments of an earlier era, the defending (previous year's) champion was automatically placed in the final round. The defending champion was thus "moved" as the winner, and an "amendment" process perfected the identity of the new challenger-except that no "primary amendment" is tested against the "main motion" until the very end. See supra note 39. In bowling competitions, on the other hand, $E$ must defeat all competitors to win, while in tennis $E$ might play $D$, with the winner 


\section{ens to increase dissatisfaction because unavoidably disappointed coali- tions would always recognize their positions. ${ }^{138}$}

then playing against the winner of a match between $B$ and $C$. The latter format thus allows "substitute amendments" while the former does not, but the systems are quite similar.

Round-robin tournaments, in which every competitor plays every other, produce "Condorcet champions" only when one athlete or team emerges undefeated. Otherwise the intransitivity is rather plain and some point or preference system is necessary to produce a winner. The fact that round-robins often produce tarnished champions explains, I think, why they are rarely used in athletic tournaments where a winner is sought. Moreover, the last round in a round-robin may prove unimportant in determining the winner, while the elimination format guarantees a climax in the last round. The psychological and financial importance of such a climax is obvious to followers of professional baseball (and to a lesser degree in football and basketball) where elimination series are used after long round-robins, and exhaustive round-robins are plainly not wanted. The controversy over the initiation of a final elimination series in collegiate football highlights this issue.

A fair number of competitions, such as golf tournaments with qualifying rounds, resemble plurality votes with runoffs in the sense that some entrants are excluded in the first round even though they might have succeeded if allowed to complete the competition. But there is little need for a complete survey of the counterparts in deliberative, political, and athletic competitions. The point is that where intransitivity is common, there is a fair amount of variety. Only "succession competition" is not found, and it would be nonsensical in most athletic competitions except where the hero is asked to pull swords out of rocks like (soon-tobe King) Arthur, or to slay foes. The additional variety when more than one winner is sought (in political and in athletic competitions, such as seats in a crew, or members of an Olympic team) simply reinforces this point.

138 This is so even if the round-robin system provides for a point system to determine the winner in the event that no alternative survives undefeated. Losers simply could (in some sense correctly) object to the use of the particular point system.

Suppose there are four candidates $A, B, C$, and $D$, eleven voters, and a round-robin system with points. The results of the round-robin are as follows: $A$ defeats $B(8-3), A$ defeats $C(6-5)$, $A$ loses to $D(1-10), B$ defeats $C(7-4), B$ defeats $D(7-4)$, and $C$ defeats $D(10-1)$.

\begin{tabular}{lccccr}
\multicolumn{5}{c}{ Opponent } \\
& \multicolumn{1}{c}{$A$} & $B$ & $C$ & $D$ \\
\hline Points & $A$ & - & 8 & 6 & 1 \\
scored by & $B$ & 3 & - & 7 & 7 \\
& $C$ & 5 & 4 & - & 10 \\
& $D$ & 10 & 4 & 1 & -
\end{tabular}

Note that, first, there is cycling: $A$ defeats $B$ who defeats $C$ who defeats $D$ who, in turn, defeats $A$; second, $A$ and $B$ each have two victories while $C$ and $D$ each have one; and third, the raw point totals are $A$ with $15, B$ with $17, C$ with 19 , and $D$ with 15 . Regardless how the winner is picked, someone is going to be "dissatisfied." If $C$ is the winner because of his high raw point total, $A$ and $B$ will be dissatisfied not only because they defeated $C$ head-to-head, but because $C$ has only one victory to their two. If five extra points were awarded for each victory so that $B$ has the greatest total, $C$ might object that five points is too many and $A$ and $D$ might object that the use of raw points overpenalizes their single drubbings. Moreover, the use of raw points instead of binary (win or lose) results often empowers one competitor to "choose" the winner from among other competitors. Thus, if the match between $C$ and $A$ is scheduled last, 
This last point is worth emphasizing because it also is useful in explaining other elements of parliamentary law. There are two strategies for dealing with the unavoidable dissatisfaction associated with the voting paradox. The first is to educate voters about its causes and to create a procedure, like the random selection of voting order, that is fair in the face of the impossibility of real majoritarianism. I know of no voting system which has tried this approach, possibly because of ignorance about collective choice problems. The second strategy is to avoid open confrontations with the voting paradox whenever possible, and much as a two-party system may limit such confrontation, so too the avoidance of round-robins may limit dissatisfaction. ${ }^{139}$ Put simply, each member may not compare notes and may ignorantly believe that a group's decision is a Condorcet choice even though it is not the member's first choice; a round-robin disabuses the member of this notion and generates dissatisfaction whenever there are cycling preferences. Perhaps the plainest illustration of this structural disinclination to reveal the presence of the voting paradox is that all parliamentary guides require supermajority votes or the clearance of - other hurdles before once-defeated alternatives may be reconsidered. ${ }^{140}$ The dominance of the motion-and-amendment process can

at some point $C$ could see that even a close victory over $A$ would not allow $C$ to beat $B$, so that $C$ might relax and allow $A$ to collect more raw points, if he were so inclined.

139 See supra note 52 and accompanying text. I admit to using the "dissatisfaction" idea, supra text accompanying notes $65-67$, as an explanation rather than as an hypothesis at this point.

The assumption, or conviction, in the text is that the revelation of cycling preferences and the importance of order is undesirable from the parliamentarians' perspectives because the underlying collective choice problem is unsolvable and because it may cause participants to object to all procedures, not just to those that arbitrarily resolve voting paradoxes. My own view is that knowledge is not so dangerous and that a reasonable strategy for parliamentary guides would be to explain the insolubility of voting paradoxes and to offer a means of reaching decisions in their presence. But the bulk of the text undertakes the positive task of explaining decisionmaking processes as they exist and not as they might be. The notion that decisionmaking processes may suppress evidence of voting paradoxes is a useful one for this task. And the processes may have evolved in this way not as a product of frightened designers but as a result of dissatisfaction by ignorant users. The discussion in the text goes on to explore this possibility.

140 See supra note 42 , discussing obstacles to reintroduction. Perhaps the best way to see that the rules suppress evidence of the nonexistence of a "real" majoritarian choice is to imagine what the rules would be like if citizens widely and deeply understood voting paradoxes. Manuals might advise more debate, discuss the importance of order in determining outcomes, and even advocate a random selection procedure in the face of cycling majorities. It would not be at all surprising to find a thoughtful parliamentarian providing for automatic 
thus be explained through the dissatisfaction idea by noting that any evolutionary step away from this process would either miss Condorcet winners and create avoidable dissatisfaction, or reveal a majority's preference for another alternative and increase unavoidable dissatisfaction as well as transaction costs. ${ }^{141}$

reconsideration of all alternatives when a voting paradox materializes. That we find none of this is, I think, strong evidence that the authorities on parliamentary practice, consciously or (almost surely) not, stayed away from any devices that would emphasize the presence of a voting paradox and its accompanying unavoidable dissatisfaction.

141 It is tempting to believe that there is an important role for lotteries in democracy, in general, and in finding Condorcet winners, in particular. Positions were filled by lot in ancient Athens, but this method has fallen into disfavor among modern commentators. See E. Stavely, supra note 7, at 180-81 (describing unusual method of lot to determine tribal order of Roman voting with the result that early votes were disproportionately meaningful); Kuflik, supra note 12 , at 311-12 (lotteries fail to encourage exchange of information and would exacerbate problems of discontinuity).

Insofar as procedure in deliberative assemblies is concerned, however, lotteries may even be a regular source of Condorcet winners. Imagine a group of 101 people, where 50 most prefer to have candidate $X$ and least prefer $Z, 1$ prefers $Y$ followed by $X$ and then by $Z$, and 50 prefer $Z$ followed by $Y$ and then $X$. $Y$ appears to be an obvious Condorcet winner, or "compromise," because 51 voters prefer $Y$ to $X$ and 51 voters prefer $Y$ to $Z$. But a fourth option might be a lottery in which a fair coin will be tossed to determine whether $X$ or $Z$ is employed. If the 100 members who rank $Y$ second only weakly prefer $Y$ to their third choice, then they will favor such a lottery which gives their first choice a $50 \%$ chance of success. It thus seems as if a lottery will sometimes, or even often, be the real Condorcet winner for it can defeat the compromise that was at first blush thought to be a Condorcet alternative.

This startling possibility was introduced in Zeckhauser, Majority Rule with Lotteries on Alternatives, 83 Q. J. Econ. 696 (1969), where it was shown that whenever a lottery seems successful on these grounds, the lottery will lose in a head-on comparison to one of the original alternatives. Thus, the lottery, $\mathrm{L}$, loses to $X$ because the 50 members who most prefer $X$ obviously prefer $X$ to a $50 \%$ chance of $X$, and the one voter who most prefers $Y$ and next prefers $X$ also obviously prefers $X$ to a toss between $X$ and $Z$. Since the previous paragraph illustrates both that $\mathrm{L}$ defeats $Y$ and $Y$ defeats $X$, the preferences cycle and the paradox is not avoided. The lottery is thus not a Condorcet-promoting innovation, and its absence from most democratic decisionmaking is not at all surprising. For some of the later important work on lotteries, see Fishburn \& Gehrlein, Towards a Theory of Elections with Probabilistic Preferences, 45 Econometrica 1907 (1977); Shepsle, A Note on Zeckhauser's "Majority Rule With Lotteries as Alternatives: The Case of the Paradox of Voting," 84 Q. J. Econ. 705 (1970).

There are a number of conclusions one can draw from this wonderful insight into lotteries. First, preferences (among more than two alternatives) that appear to yield Condorcet winners may actually be cycling preferences. A lottery may defeat the apparent Condorcet winner, but since such a lottery can always be defeated by one of the original alternatives, the situation refiects cyclical preferences. Inasmuch as this discouraging turnabout depends on the relative weakness of the second choice, the problem does not arise if the first 50 voters liked $Y$ a fair amount (more than one-half "the distance" between $X$ and $Z$ ), because they would not prefer a lottery between $X$ and $Z$ to $Y$ 's emergence as the winner. Given that it is difficult to know how often actual preference intensities fit this description, one cannot go so far as to conclude that motion-and-amendment (or round-robin) voting must be defended on the basis of its ability to 


\section{B. The Occasional Attraction of Succession Voting}

We have seen that the motion-and-amendment process steers clear of avoidable dissatisfaction and suppresses the development of unavoidable dissatisfaction. Nevertheless, because dissatisfaction is generated when no Condorcet choice is available and some voters compare notes, there is likely to be some evolution in the direction of succession voting. Indeed there is no reason to think that succession voting will reveal cycling more often than motion-and-amendment voting and there is an advantage to the former decisionmaking procedure that may sometimes offset the ability of the latter to deliver any available Condorcet choice; well-informed and clever chairpersons can manipulate motion-and-amendment voting by recognizing favored members first so that their motions need not survive a great many votes. ${ }^{142}$ This aspect of the chair's power is only increased by

produce " $51 \%$ winners" rather than on the ground that it delivers Condorcet winners. And it remains true that the round-robin and motion-and-amendment processes will deliver a Condorcet winner, if any exists, but in order to accomplish this end, voters must be offered appropriate lotteries as alternatives-which they can then reject.

Second, the more one thinks the lottery analysis persuasive because middling preferences are indeed relatively weakly held, the more the choice among voting types needs to be recharacterized. After all, if true Condorcet winners are rare because non-Condorcet lotteries defeat seemingly Condorcet winners, then the ability of a voting type to produce seemingly Condorcet winners can hardly explain the uniformity of that voting type. My own inclination is to think that lotteries will only occasionally beat compromise winners, such as $Y$ above, but if that intuition is wrong, then the ability of "extremists" or "underrepresented minorities"depending on one's perspective of the group at issue-to emerge in plurality voting looms large as an explanatory variable. Inside deliberative assemblies, one-at-a-time voting, such as motion-and-amendment or succession voting, may have emerged because it disfavors strongly held minority views; outside such assemblies, plurality voting permits such minorities or extremists to be included in the decisionmaking process. The picture is one of political compromise or, some would say, false advertising: allow all factions to be represented but, ultimately, by excluding plurality voting when actual decisions are made, make minority factions relatively powerless. Of course, the ability of such factions to engage in logrolling processes alters this simple calculus substantially. See W. Riker \& P. Ordeshook, supra note 27, at 112-13. But inasmuch as I have introduced the role of lotteries as an occasional possibility and not as a probability, there is little point in continuing the exploration this far afield.

142 See supra text accompanying note 66 . For a chair to use voting order to manipulate the motion-and-amendment process, the favored proposal must be among alternatives that cycle. If there is a Condorcet winner, a virtual impossibility when there is time to introduce an enormous number of competing alternatives, the chair cannot manipulate the outcome since that alteruative will emerge regardless of the order of voting. See supra note 134. If voting is sincere, the chair will try to call on a favored proposal first (making it the last to be voted on) and will try to recognize last any proposals that defeat the favored proposal (making them the 
its ability to rule secondary amendments "not germane" and hence unavailable for immediate consideration. ${ }^{143}$

In contrast, succession voting often favors later-but not too lateentries into the fray, but since it is difficult for the chair to judge the quantity of alternatives yet to be proposed, it is difficult to position one's favorite correctly. ${ }^{144}$ It is no accident, I think, that Robert's Rules and many other guides to parliamentary law switch to the suc-

first to be voted on). This goes a long way toward ensuring that the chair's favored proposal will win.

Assume, for example, that among the three alternatives 1, 2, and 3, that 1 defeats 2, 2 defeats 3 , and 3 defeats 1 . A chair wanting 3 to win will call on 3 first, allowing 3 to be the main motion, and will call on 2 last, so that it will be the secondary amendment, leaving 1 to be the primary amendment. This order forces the early exit of the only alternative that beats 3 , (since 2 loses to 1 in the first vote). Once 2 is eliminated, 3 will win in a comparison with the other alternative, 1 .

143 An amendment is improper, and thus not allowed, if it is not germane. To be germane to the question potentially amended, the amendment must "in some way involve the same question." $H$. Robert, supra note 1, at 113. Similarly, "[g]ermane means relevant to, and having direct bearing upon, the subject of the motion which the amendment seeks to change." A. Sturgis, supra note 23 , at 182 . Since these guidelines contain room for discretion, the chair can use its position to declare borderline motions "not germane" if the chair opposes the proposal. An assembly can overrule its chair through an appeal, but there are a variety of reasons to expect such appeals to be rare and even more rarely successful. See H. Robert, supra note 1, at 113-15 (going into detail on "determining the germaneness of an amendment").

144 With sincere succession voting, it is difficult (for the chair) to know what is the best position, but there is no doubt that the worst position is being voted on first. As we have seen, even a Condorcet winner can lose in this position. See supra note 133. This makes it a little more dangerous for the chair to pick its favorite first when using the motion-and-amendment procedure, for after this is done, it is possible that a member could move to create a blank after which succession voting could be used. If no specific order of voting is required by the rules (e.g., amounts of money), then what was previously the main motion is voted on first. See, e.g., H. Robert, supra note 1, at 139-40 ("If a name has been struck out to create a blank, however, it comes first in the order of names to be voted on."). But note that in many, if not most, cases, the rules will require a certain order based on the nature of the blank. See supra text accompanying notes $83-95$. Generally speaking, this rule removes the chair's power to manipulate the outcome by recognizing the proposals in a strategic order.

Interestingly, alert members may sometimes use these rules to their advantage. For example, suppose there were three alternative amounts proposed for some project, $\$ 100, \$ 500$, and $\$ 900$, and the adopted rules required highest to lowest voting when filling a blank to spend money. Assume no alternative to be favored by an absolute majority, but $\$ 900$ to be a Condorcet winner. A veteran parliamentarian who opposes $\$ 900$ would move to create a blank, since he knows that the $\$ 900$ option would be eliminated in the first vote if voting is sincere. If the rules provide that a motion already made becomes the first proposal voted on after a blank is created, then the wily dissident may have an even easier time, moving to create a blank if $\$ 900$ is the first motion made. A clever parliamentarian, who favors lower spending, may also try to add $\$ 950$ or some similar proposal to the list of alternatives that will be 
cession process only for filling blanks, ${ }^{145}$ when many alternatives are proposed and cycling preferences are quite likely. The codes can be regarded as evolving along the lines of, or as having adopted, the following reasoning: (1) employ the motion-and-amendment process when there are few alternatives because it promises to find any Condorcet choice without encouraging unavoidable dissatisfaction; (2) when there are numerous alternatives likely to be proposed, facilitate a switch to succession voting because a Condorcet winner is quite unlikely and the switch will make it difficult for the chair to manipulate the order of recognition to unfairly influence the outcome; and (3)

considered in succession. This addition is likely to siphon off some support from the $\$ 900$ proposal.

The difficulty the chair or anyone else faces in determining the best position when there is sincere succession voting is illustrated by considering three voters, $A, B$, and $C$, choosing from options $1,2,3$, and 4 , with the following preferences: A: 1234, B: 2341, C: 3412 . There is cycling, since 1 defeats 2 which defeats 3 which defeats 4 which, finally, defeats 1 . But if the voting order is 1234, then the second proposal voted on (2) wins with $A$ and $B$ voting for it; and if the voting order is 2134 , the third proposal (3) wins unanimously; and if the voting order is 3421 , the fourth proposal (1) also wins unanimously assuming the voters are still willing to accept any option. Thus, the best position is a function of the specific voting order, while the worst position is always the first.

With sophisticated voting the question is considerably more complex. If one assumes that the voters have a very good understanding of cycling and of Condorcet winners, but refuse or are unable to trust each other (so that there are no binding deals), then it becomes fairly attractive to go first. Also assume that propositions are voted on in numerical order. If 1 goes first, 1 will win; if 2 goes first, 2 will win; if 3 goes first, 3 will probably win; but if 4 goes first, 4 will probably lose. Initially note that 3 beats 1 and 4 , and 2 defeats 3 and 4 . If 1 is eliminated first, 2 is a Condorcet winner among the remaining alternatives since it defeats 3 and 4 . Thus, if 1 is the first option voted on, strategic and well-informed voters will realize that the (only) real choice is between 1 and 2 . Since 1 beats 2,1 will win; thus voting on 1 first assures l's victory. Similarly, 2 will win if it is voted on first because without 2,3 is a Condorcet winnerfor it beats 4 and 1-so when 2 is voted on first, voters choose between 2 and 3 , and 2 is preferred.

It is more difficult to analyze the situation where 3 or 4 is eliminated first, since the remaining three alternatives cycle ( 1 defeats 2 which defeats 4 and 3 , but 4 and 3 defeat 1 ). Since 3 defeats two of the three cycling alternatives, one might guess that voters would vote in favor of 3 in the first round. Similarly, since 4 loses to two of the three cycling alternatives, it may be safe to assume that it will lose in the first round. It is possible, of course, that these sophisticated voters would first consider the identity of the alternative that emerges out of the cycling before they vote for or against 3 or 4 in the first round. But since this matter itself depends on the order of consideration it is quite a strenuous calculation, and the reader will be spared further spinnings.

145 See, e.g., G. Demeter, supra note 23 , at 74 ("Whenever numerous amendments are spontaneously suggested or simultaneously called out by the members, such suggestions or calls are treated not as formal amendments or proposals, but as suggestions for filling blanks."). 
when succession voting exposes unavoidable dissatisfaction, tinker with the order in which proposals are considered.

Steps (1) and (3) were developed in Part II. There are two additional points to note in connection with (2). First, parliainentary law encourages the switch to filling blanks, or succession voting, by limiting the number of amendments that can be pending with regard to any motion and by disallowing additional primary or secondary amendinents once earlier entries have been approved. For example, innagine a meeting of a foundation's directors, proceeding under $R o b$ ert's Rules, in which $A$ moves that a research center be established and that candidate 1 be einployed as its director, and $B$ moves as an amendinent that 2 be employed as the director. No alternative priinary amendinent is now permissible, although $C$ may urge the group to vote against $B$ 's amendment, and may make clear that after its rejection $C$ will propose that 3 be employed. ${ }^{146}$ If $B$ 's proposal passes, however, no such amendment is permitted unless it overcomes the hurdles to reconsideration. ${ }^{147}$ Even if $C$ can fraine the proposal as an acceptable secondary amendment, for instance by proposing that $B$ 's ainendment be amended to read that 2 will be the director, with 3 the "chancellor" in charge of 2 and the rest of the institute, it is clear that $D$ cannot get a vote on the employment of candidate 4 as the head of the institute unless either the primary or secondary amendment is defeated. In short, the rule against tertiary amendments, which blocks consideration of $D$ 's proposal, the rule that only one primary amendment and one secondary amendment are permitted at a time, and the rule against easy reconsideration of prior questions serve to encourage or even force a switch from the motion-and-amendment format to succession voting, in the form of filling blanks. If $A$ did not originally suggest a blank, $C$ or $D$, or even the chair, will move that a blank be created in $A$ 's motion, after which any number of suggestions for filling it may be put forward. ${ }^{148}$ The motion must be voted on, ${ }^{149}$ but if there are numerous members with different preferences it

146 H. Robert, supra note 1 , at 111.

147 Id. at 111-12 (amendment cannot "raise questions already decided").

148 Id. at 136-37 (A blank can be created in three ways: a proposal can originally contain a blank, a member can move to create a blank, or the chair can suggest creating a blank.).

149 Id. at 137 ("The motion to create a blank requires a second, but it is neither debatable nor amendable; it can also be made and voted on while a primary or a secondary amendment relating to the subject specification is pending."). 
is likely that a majority will want to compare $D$ 's and other proposals without the precondition of defeating the pending amendments.

The second point worth noting about parliamentary law's occasional switch to succession voting is that it destroys or even penalizes the chair's usual ability to manipulate outcomes through strategic recognition of speakers. In motion-and-amendment voting it is normally advantageous to make the original motion and, therefore, to have one's proposal considered later rather than earlier, because, secondary amendments must win two head-to-head battles to prevail while a main motion need fend off only the surviving amendment. The chair has the power to call on a friendly member or to appoint a committee, whose report will often constitute the inain motion, when the situation favors the first speaker, whose proposal will be voted upon last. In the preceding exainple, if the chair recognizes $A, B$, and $C$ in that order, and no further proposal or switch to succession voting is made, candidate 1 has the advantage because this candidate need only compete with the survivor of the competition between 2 and 3. The story changes, however, when a switch to succession voting is made. Other candidates' names are accepted and each name, including those already proposed in the motion-and-amendment process, is debatable and voted on until one receives majority approval. ${ }^{150}$ If, as Robert and Sturgis suggest, the proposals are voted on in the order in which they were put forward, ${ }^{151} A$ 's candidate is now considered first and, unless voters are perfectly informed and strategic, is disadvantaged because voters preferring any other proposal on the list may vote against the first. ${ }^{152}$ Not only do the rules switch to succession voting just where a Condorcet winner is most unlikely and where the chair would have too much power under motion-and-amendment voting, but also the rules are likely to penalize or, more optimistically, deter the chair from behaving strategically in the motion-and-amendinent process. Since the chair never knows when a switch to succession voting will occur, the chair may be wise not to risk subsequently disadvantaging its own views by trying to wield influence in the motion-

$150 \mathrm{Id}$.

151 Id. at 137-38; A. Sturgis, supra note 23, at 185. Sturgis suggests that every matter be voted on in the order proposed, while Robert recommends arranging the order according to certain guidelines, such as least to greatest likelihood of success, or highest to lowest. See supra text accompanying notes 72-77.

152 See supra note 144 . 
and-amendment process. Robert's Rules may change the order of consideration when numbers or dates are needed to fill blanks because if there are single-peaked preferences it will be less confusing for the numbers or dates to be in some comprehensible order. ${ }^{153}$

It is easy to make too much of this anti-chair quality of the switch to succession voting because, as discussed at some length in Part II, there are many other methods for arranging the voting order on proposals to fill blanks. The other methods, as just noted, may be more appropriate for sums of money and dates than for names, and it is only fair to note that the other methods (such as "highest to lowest") take away the chair's recognition power without penalizing the chair. No authority suggests, however, that blanks be filled by beginning with the last proposal and continuing toward the first, until one receives a majority. Such a method might leave the chair with a bit of an advantage, and it is therefore interesting that it is a method which is simply not part of the evolutionary story.

The anti-chair quality of succession voting goes a long way toward explaining why, when parliamentary law switches away from motion-

153 See $\mathrm{H}$. Robert, supra note 1 , at $135-40$. This idea is very clear if one considers Robert's example of the motion to sell an organization's headquarters for not less than $\$$ - It is virtually impossible that any member would not have single-peaked preferences, believing, for example, $\$ 50,000$ too little to get for the headquarters, $\$ 80,000$ an acceptable amount, but $\$ 100,000$ inferior to $\$ 80,000$ as a sale price. Furthermore, it might indeed be confusing to the members to vote on the amounts in the order they were proposed, if the order were $\$ 80,000$, $\$ 50,000, \$ 120,000, \$ 100,000$, and then $\$ 70,000$.

However, whether it is best to go from smallest to largest or largest to smallest is not clear, and there is variety in the rules on exactly this point. See supra notes 87-94 and accompanying text. Robert, in this example, recommends going from smallest to largest, because "those who are willing to sell for the smallest amount, and some additional members, will be willing to sell for the next larger sum, and so on, until the smallest sum for which the majority is willing to sell is reached." Id. at 139.

Not only can voting by order of proposal miss Condorcet alternatives but also-in the face of imperfect information-it can even miss an alternative that enjoyed the support of an absolute majority. If every member prefers $\$ 100,000$ to $\$ 80,000$ but does not dislike $\$ 80,000$, then $\$ 80,000$ might be adopted if it is offered first because voters might fear the adoption of $\$ 50,000$. This problem could not arise under the motion-and-amendment procedure, because $\$ 100,000$ would defeat $\$ 80,000$ in a head-on comparison.

One could solve much of this problem by turning succession voting into a form of "approval voting," see infra note 162 , by "voting" on all proposals and then comparing those receiving majority support. Kramer, supra note 26 , at 289 , seems to believe that something of this sort is practiced under parliamentary rules, but in fact every authority stops the process as soon as one proposal gets a majority. See, e.g., L. Cushing, Manual, supra note 23, at 58 (if a proposal "should be carried in the affirmative, every question for more would be precluded"). 
and-amendment voting, the switch is to succession and not to plurality voting. Plurality voting also suffers in comparison to succession voting when one considers the possibility of tie votes; even sophisticated voters may miss a Condorcet alternative when the chair has tiebreaking power in plurality voting. ${ }^{154}$

The occasional switch to succession voting is easily understood when the likelihood of a Condorcet winner is small and when the bias of the motion-and-amendment format in favor of earlier proposals is easy to exploit. It may not be so easy to know, however, when such circumstances are present, and a switch is sensible. Some observers may insist that cycling majorities are quite rare even when the alternatives under consideration concern candidates, dates, or sums of money, while others may sense that a great many decisions at formal meetings are reached where preferences are not single peaked. If voting paradoxes are common, there is an argument for regularly favoring succession voting, where the chair's power of recognition is limited, over the motion-and-amendment process. The tradeoff is clear: Succession voting will miss a few Condorcet winners in return for removing some of the chair's power to determine results.

With this in mind, it is interesting to note that deliberative assemblies outside the United States sometimes use succession voting where all the U.S. guides use the motion-and-amendment format. These foreign systems still entertain motions and shun plurality voting, thus eliminating the easiest way to miss Condorcet choices, but under these rules amendments may be considered in the order submitted, ${ }^{155}$ by addressing the largest changes first, ${ }^{156}$ by first considering proposals to delete portions of the main motion, ${ }^{157}$ in the reverse of the order submitted, ${ }^{158}$ or as the presiding officer decides. ${ }^{159}$ The last two meth-

154 See infra note 168 . It is also possible that plurality voting generates higher transaction costs than does succession voting, because an assembly using the latter format may find a winning alternative in an early proposal. Finally, an aesthetic, or political, attraction of succession voting over plurality voting is that it completes the decisionmaking process with an apparent absolute majority voting in favor of the winning alternative.

is5 V. Herman \& F. Mendal, supra note 109 , at $677-93$ (listing a number of national legislatures, including those of Bulgaria, Costa Rica, Denmark, and Zambia, where proposed amendments are considered in the order submitted).

156 Id. at 679, 684 (Belgium and Ivory Coast).

157 Id. at 682, 689 (France and Senegal).

158 Id. at 689 (Republic of Korea).

159 Id. at 681, 688 (Fiji and Norway). 
ods favor the chair, but there is striking variety where (no one rule is clearly best and when) dissatisfaction is likely.

\section{Voting Processes Outside of Parliamentary Law}

\section{Revisiting the Choice Between Processes}

The evolutionary success of the various forms of plurality voting outside parliamentary law redirects attention to its absence within parliamentary law. This absence may have seemed well explained in Section A of Part III by the ability of motion-and-amendment voting to deliver a Condorcet choice, when one exists, and to complete deliberation with a majoritarian-looking, or fifty-one percent, vote. But that explanation is weakened by the presence of plurality voting elsewhere. Why, for example, is plurality voting so attractive in the election of legislators and other representatives both in the United States and elsewhere? The straightforward answer creates a puzzle even as it solves one; plurality voting is more attractive than motion-andamendment voting because in the context of general elections the importance and bias of order is too obvious. If $A, B$, and $C$ are candidates for a seat on a city council it would seem terribly unfair for $A$, or any other candidate, to sit out a round while the other candidates first compete for the chance to run against $A .^{160}$

There are three ways to describe this reasonable and negative reaction to the motion-and-amendment process in general elections that do not force us to revisit the remarkable uniformity of this process inside deliberative assemblies. First, citizens might be more concerned about the perils and expense of additional election campaigns than about the voting paradox. If $B$ and $C$ must first compete, with the winner then facing $A, B$ and $C$ need to finance two campaigns (which may not be entirely complementary because of the opponents' different identities), and they have additional opportunities for blunders, inconsistencies in public statements, and so forth. This point is especially powerful if there are more than three candidates. The burden of running four or five campaigns, while other candidates need

160 If $B$ and $C$ seek the nomination of a political party that is different from $A$ 's, they may of course have to compete in an extra (primary) contest. Each candidate chooses such party affiliation, however, and no doubt expects some offsetting advantages from the affiliation. 
only run one or two, is so obvious that plurality (or elimination) ${ }^{161}$ voting will be much more attractive than motion-and-amendment voting in general elections. ${ }^{162}$ Inside dehiberative assemblies, of

161 Though elimination voting - in which competitors pair off and only advance to the next round if victorious-leads to more rounds of voting than plurality voting, it should be more attractive to most citizens' sense of fairness than motion-and-amendment voting, since both finalists would have to run roughly the same number of campaigns. If eight candidates, $A, B$, $C, D, E, F, G$, and $H$, were running for one office, and elimination voting were used, then cach and every candidate would need exactly three victories to win. The winner of the competition between $A$ and $B$, would, in the second round, face the winner of that between $C$ and $D$, with the winner of that vote facing the survivor of the "bracket" containing $E, F, G$, and $H$ in the third round. Conversely, if an extended motion-and-amendment procedure were in use, the two candidates in the earliest round must win seven rounds ( $G$, for example, would need to defeat $H$, then $F$, then $E$, and so forth), whereas the candidate starting in the latest round (analogous to a main motion in parliamentary procedure) need win only one round to be victorious. See supra note 137 for a discussion of the different selection procedures found in athletic competitions.

Note that while the candidate or competitor's position in the "draw," so to speak, matters more in the motion-and-amendment procedure, it also matters in elimination voting, especially if the identity of the second place finisher is significant. Imagine a country or organization that uses an elimination procedure to elect its president, and the losing finalist takes the office of vice president, or has great power to influence the choice among platform positions or vicepresidential candidates. If candidate $A$ is the Condorcet choice, the elimination procedure guarantees $A$ 's victory, since $A$ would never lose a pairwise comparison. But the only candidates who have a chance at the second slot are those in the opposite half of the draw from $A$, because those in $A$ 's half of the draw will encounter $A$ before the finals and be eliminated, regardless of how they would fare against the remaining candidates. Thus, position in the draw can be the most important factor in determining who wins the vice-presidency, or appears to be in second place.

162 As mentioned earlier, succession voting is never found in general elections. Given the nearly universal existence of succession voting in parliamentary procedure, however, it would not be shocking to find the procedure outside of assemblies in a general election. The ballot could contain a list of candidates and voters would mark them 'yes' or 'no.' If a majority of voters marks 'yes' by the name of the first candidate listed, then that candidate would be the winner and the process would be stopped. If not, the votes for the second candidate would be counted, and so on until a candidate receives a majority. To prevent the absence of a winner, this procedure might include the rule that the last candidate listed is a "default" candidate. Voters would know that if no candidate receives a majority the last candidate will win, and they would take this into account in their voting. A 'no' vote for the second-to-last candidate, for example, would obviously be a 'yes' vote for the last candidate listed.

The uniform absence of anything like the succession voting procedure just described, can be explained, I think, by the existence of "alternative voting" and similar procedures. In the simplest form of alternative voting each voter ranks the listed candidates first to last, and if no candidate receives a majority of first-place votes, then the candidate with the least number of votes is eliminated and the second place votes of that candidate's supporters are redistributed to the remaining candidates as indicated. This procedure of eliminating the candidate with the least votes and redistributing the supporters' votes to the next-highest "alternative" is repeated until one candidate has a majority. See supra note 121 (general description of preference 
course, there is no corresponding expense to extra rounds of competition.

The preceding explanation is soinewhat weakened because the motion-and-ainendment process is not normally used in any elections, ${ }^{163}$ even when expensive cainpaigns are not waged. Thus, athletic teams elect captains, and ad hoc assemblies elect presidents, not by the motion-and-amendment process, but rather through plurality voting. Such elections may simply imitate inore public elections, where cainpaign expense is a crucial variable, or simply save the transaction costs of multiple rounds of voting, which might be more efficiently conducted in deliberative bodies. But the basic distinction would surely be more convincing if plurality voting were limited to elections which follow significant cainpaigns by the candidates.

A second explanation for the doininance of plurality over motionand-amendment voting in general elections draws on the important role of the chair in deliberative assemblies. If motion-and-amendment voting were to be used in general elections, who would set the order of competition? The chair is normally elected inside deliberative assem-

voting). Alternative and "approval" voting, where voters "approve" as many candidates as they like and the winner is the candidate receiving the most approvals, are discussed in $M$. Dummett, supra note 48 , at 168-75, and E. Lakeman, supra note 4, at 63-65.

A comparison of the (not unusual) alternative vote and the succession method reveals that the alternative vote is less complicated and diminishes the importance of placement order on the ballot. It is less complicated because voters do not need to be fully aware of the procedure when ranking the candidates under the alternative vote method, but they must take procedure into account when trying to vote under succession voting. For instance, if five candidates $A, B$, $C, D$, and $E$ are on a ballot in that order and one's preferences are DBACE respectively, it is not at all obvious how to vote under succession voting.

As between succession voting and approval voting, approval voting once again diminishes the importance of placement order on the ballot. Additionally, the former would seem more likely to miss the most popular candidate if this candidate's name is placed late in the voting order. Though approval voting is used only for some honorary societies, it recently has been suggested as useful in national primaries and elections. W. Riker, supra note 43 , at 88 , citing Brams \& Fishburn, Approval Voting, 72 Am. Pol. Sci. Rev. 831 (1978). See generally S. Brams \& P. Fishburn, Approval Voting (1983) (arguing that approval voting is superior to alternative types of plurality voting).

In short, succession voting may not be found in elections because similar procedures, alternative and approval voting, are probably fairly regarded as superior to succession voting.

163 The motion-and-amendment procedure is usually dismissed by authorities on politicswhen it is discussed at all-as somehow appropriate only for committees within legislatures. It is, of course, a procedure that is associated with committees. See, e.g., D. Black, supra note 41, at 3-4; M. Dummett, supra note 48, at 61 . Most studies that focus on electoral procedures simply ignore the motion-and-amendment procedure. See, e.g., E. Lakeman, supra note 4; B. Grofman \& A. Lijphart, supra note 121. 
blies, so its role in recognizing meinbers can be accepted as "fair" or as part of the larger majoritarian process, but it is inore difficult outside such situations to think of the order-setting inechanisin. The point is really an anthropological one; while it may be difficult to inagine any evolutionary inechanism solving the problem of ordersetting in motion-and-ainendinent general elections with three or inore candidates, if one were soinehow established, its continued survival would be unsurprising. It is easy to imagine a deinocracy in which the incumbent is prohibited from running for reelection, but may noininate a successor who is then approved or disapproved by the electorate. Some corporate positions appear to be filled in this 1nanner, but it happens that this is not a fainiliar format in general elections. ${ }^{164}$ Thus, the absence of a natural figure to set the all-important order of consideration in motion-and-ainendinent voting ainong multiple candidates inay explain why this election type is so rarely found outside of deliberative assemblies.

The third explanation exploits the ability of plurality voting to suppress evidence of a voting paradox. When elections involve numerous candidates, a Condorcet winner is quite unlikely. ${ }^{165}$ In this situation a round-robin process is very unattractive because it will inevitably expose the presence of cycling preferences. Its strength, the guaranteed discovery of a Condorcet winner without biasing the results through the order of consideration, ${ }^{166}$ is unimportant when there is no

164 In some sense a recall procedure is related to this motion-and-amendment idea, because the incumbent is recalled or not, without any explicit comparisons to candidates who might fill the vacancy created by the recall vote.

165 See supra note 81 . Certain school board elections, presidential primaries, and contests fit this description. When a committee chooses the prize winner, for example, a large number of entrants may be narrowed by overwhelming or even unanimous consent to a group of five or ten finalists, but it is most unlikely for there to be an ultimate Condorcet winner. Indeed, the members of such committees often may be appointed precisely because their tastes are known to be diverse, so that a Condorcet winner is especially unlikely.

It has been noted that a majority of voters in a group of individuals who are only slightly more likely to make a "right" choice rather than a "wrong" choice will be decidedly more likely to settle on the "right" choice than any individual. If, in some settings, an average voter is only slightly more likely than not (or $51 \%$ ) to be correct, and if one requires only $51 \%$ of the vote to carry a proposal, "then the probability that a 51 percent majority is correct in its judgment when 100 are voting is 51.99 percent. For an electorate of 500 , the probability that a 51 percent majority opinion is correct is 59.86 percent. When 1,000 are voting the probability is 69 percent. And when 10,000 are voting, it is 99.97 percent." Kuflik, supra note 141, at $300,305-06$.

166 See text accompanying note 124 . 
Condorcet winner. Motion-and-amendment voting has the same unneeded strength, ${ }^{167}$ but, because it does not test all pairs in roundrobin fashion, at least it does not always reveal the presence of cycling preferences. Plurality voting, however, never asks for such head-tohead comparisons, and therefore best conceals cycling preferences. Its great weakness is how easily it misses Condorcet winners, and the likely nonexistence of such winners in elections with numerous alternatives may explain the popularity of plurality voting outside of deliberative assemblies. ${ }^{168}$

\section{Variety Among Types of Plurality Voting}

I have used the term "plurality" voting to refer to systems which exclude at least one alternative even though no competing alternative receives a simple majority of the votes cast. Motion-and-amendment voting is not a form of plurality voting because a proposal is only excluded after it is rejected by a majority in favor of some other specific alternative. ${ }^{169}$ Elections calling for a second-round runoff

167 It guarantees the production of any Condorcet alternative, see supra text accompanying note 134 , but, again, it is very likely that no such alternative exists.

168 Returning to decisionmaking inside deliberative assemblies, the absence of plurality voting in parliamentary law, see supra notes 119-23 and accompanying text, may be further explained by the fact that sophisticated voters always will reach Condorcet alternatives except with plurality voting, where the chair's casting vote may stand in the way. The first part of this proposition is easily seen; if $A, B$, and $C$ rank three alternatives 123,231 , and 321 , so that 2 is a Condorcet choice, any voting method that would yield 1 or 3 will be overcome by a coalition of $B$ and one colleague who prefer 2 to the other result. With plurality voting, however, if $A$ is the chairperson and the chair has a deliberative and a casting vote, $B$ and $C$ must combine to beat 1 . But there will be no stable coalition; $B$ will hope their deal involves voting for 2 and $C$ wishes that both vote for 3 . One cannot, therefore, confidently predict that sophisticated voters will defeat the chair. See R. Farquharson, supra note 43, at 61, 66 (depicting a plurality vote when one voter has an additional vote). Inasmuch as it is a good thing that at least sophisticated voters reach Condorcet choices, groups with a chair might shy away from plurality voting because only in this decisionmaking system might sophisticated voters fail to reach the Condorcet alternative. Note, however, that a deliberative assembly may occasionally use plurality voting when holding its own "general election," as in selecting its chair. See, e.g., State ex rel. Reed v. De Maioribus, 131 Ohio St. 201, 2 N.E.2d 506 (1936) (concerning city council which had choice between plurality and majority voting for selection of president); State ex rel. Calderwood v. Miller, 62 Ohio St. 436, 57 N.E. 227 (1900) (plurality voting for city clerk by city council).

169 See supra note 121. A disadvantage of plurality voting is that an alternative can be eliminated based on the number of first place votes it receives, thus increasing the chances, or even making it likely when preferences are largely single peaked and a compromise is possible, that the Condorcet winner will be eliminated after the first round of voting. Conversely, no alternative will be eliminated under the motion-and-amendment procedure unless that 
between the two leading first-round candidates are plurality elections because a third-place candidate is excluded despite every competitor's failure to receive a majority and despite the excluded candidate's potential ability to triumph over any competitor in head-to-head voting.

There are many forms of plurality voting, and I mean in this section only to emphasize that this variety is entirely unsurprising. Consider the variety of objections that may be raised to $A$ 's election where the voting percentages received by candidates $A, B, C$, and $D$ are 30 , 26,24 , and 20 respectively. Voters, possibly with the help of pollsters, may realize that a majority prefers $C$ (or $B$ or $D$ ) to $A$. This dissatisfaction might not provide the evolutionary impetus for the adoption of round-robin, succession, or motion-and-amendment voting, either because of their higher transaction costs, or because previous experience or careful thought reveals the likelihood of dissatisfaction in the future under such formats. A preference for $C$ over $A$, however, may well produce calls for runoffs or for "preference" voting in the future. It may be possible, after all, to discover a Condorcet alternative even after some alternatives are excluded in the first round. ${ }^{170}$ Moreover, it

alternative loses in a head-to-head vote against some specific alternative, thus assuring that the Condorcet choice cannot be eliminated. See Kramer, supra note 26, at 289 ("The current disrepute of plurality voting in parliamentary law is well founded."). For a report of some well-publicized, modern political contests in which a Condorcet winner may have been defeated through plurality voting (even with a runoff), see S. Brams \& P. Fishburn, supra note 162 at 1-7. For a discussion of an election (the McGovern-Muskie primary contest) in which plurality voting alone may have yielded the known outcome, see D. Mueller, Public Choice 6466 (1979).

170 Plurality voting will most easily miss a Condorcet choice when it is everyone's second choice, but nobody's first choice. If the Condorcet alternative has some voters who rank it first, then systems such as plurality voting with a runoff and preferential voting (a form of which, alternative voting, is discussed supra note 162 ) are much less likely to miss the Condorcet choice.

Imagine three groups of voters voting on alternatives $1,2,3$, and 4 such that a group with eight voters has a preference order of 1423 , a group with seven voters has a preference order of 2431 , and a group with six voters has a preference order of 3412 . 4 is a clear Condorcet winner since it would handily defeat any of the three other alternatives in a head-to-head comparison. Since 4 has no voters supporting it as a first choice, however, it would be the first alternative eliminated in most plurality voting procedures.

With slightly different preferences, these more complicated plurality systems do better. Thus, if the first two groups' rankings of 2 and 4 are altered such that the group of eight now orders its preferences 1243 , the group of seven prefers 4231 , and the group of six continues with 3412 , then the results are different. The Condorcet choice is still 4 , but 4 now would win 
may be attractive to finish the election process with at least one ritual which crowns an apparent majority (fifty-one percent) winner.

If a group toys with using rankings to elicit voters' preferences, then it may seem attractive to try to minimize the "waste" of any ballots. ${ }^{171}$ The less complex a voting procedure, however, the better it

if the procedure were either plurality vote with a runoff or the alternative vote system, since 3 would be eliminated early and the last group of six voters would then support 4 .

Since 4 has a much better chance in the second example than the first, it is especially interesting to note that 4 has less overall support in the second example. In the second example, eight voters downgraded 4 (to below 2) while only seven voters upgraded 4 (to above 2). The key to 4's success in the second example was that enough voters listed it first so that it avoided early elimination.

171 Many of the innovations in electoral procedures may have been driven by a desire to reduce the number of "wasted" votes. A wasted vote is, in its simplest sense, a vote for a candidate who has no chance to win. The definition ignores the possibility that voters may use the vote not to affect outcome but simply to make a statement. When there is an independent candidate in addition to the two major parties' nominees, as there was in the 1980 presidential election, many voters who prefer the independent candidate may not vote as such because it is so unlikely that their candidate will win. They may feel their votes would be better spent on one of the two candidates with some real chance of winning. See P. Fishburn, Social Choice and Pluralitylike Electoral Systems, in B. Grofman \& A. Lijphart, supra note 121, at 198 (Seventeen percent of the voters in the 1980 election most preferred Anderson but voted for either Reagan or Carter because they thought Anderson had no chance to win.).

A system which has the voters rank their preferences and then uses these preferences in some way, clearly wastes fewer votes than simple plurality voting, where the winner is the candidate with a relative majority after a single round of voting. In the above example, if an alternative vote system had been in effect, then votes for Anderson would be less likely to have been wasted, because if neither Reagan nor Carter received a majority, then a second round of calculations would have taken place. The election officials would take all the ballots listing Anderson as the first choice and distribute these votes to either Reagan or Carter, based on those voters' second-choice indications. But see M. Dummett, supra note 48, at 214-15 (Alternative vote advocates claim that this system reduces wasted votes but they never define "waste" precisely and the real problem is often strategic, not wasted, voting.).

The single tranferable vote system, or STV, developed in response to a slightly different kind of waste. Enid Lakeman captures the essence of the system in the following passage about early nineteenth century schoolchildren: "[The] pupils were asked to elect a committee by standing beside the boy they liked best. This first produced a number of unequal groups, but soon the boys in the largest groups came to the conclusion that not all of them were actually necessary for the election of their favorite and some moved on to help another candidate, while on the other hand the few supporters of an unpopular boy gave him up and transferred themselves to the candidate they considered next best." E. Lakeman, supra note 4, at 108. The idea is both to distribute the "surplus" votes which remain after the minimum necessary to elect one representative, and to eliminate the low vote-getters and redistribute their votes if vacancies remain after the first surplus is distributed. STV is obviously used only where more than one representative from a pool of candidates is to be elected. But this is not the place to review the advantages and disadvantages of proportional representation and of various selection mechanisms. For more on the single transferable vote, see M. Dummett, supra note 48, at 266-93; E. Lakeman, supra note 4, at 105-40; Wright, supra note 121, at 125-26, 132-36; 
is likely to be regarded. ${ }^{172}$ It may also seem sensible, fair, and democratic to allow distinct minority groups to succeed in electing representatives, through cumulative or other voting systems, even though no head-to-head comparison would favor such a representative. ${ }^{173}$ But, it may seem unwise to sponsor plurality systems that splinter the majority's vote so that "extremist" groups can succeed in electing their choices. ${ }^{174}$ Clearly, there are many desirable, and sometimes

A. Lijphart \& B. Grofman, supra note 121, at 113-51; Lijphart, Pintor \& Sone, The Limited Vote and the Single Nontransferable Vote: Lessons from the Japanese and Spanish Examples, in B. Grofman \& A. Lijphart, supra note 121, at 154; Weaver, The Rise, Decline, and Resurrection of Proportional Representation in Local Goverments in the United States, in B. Grofman \& A. Lijphart, supra note 121, at 139.

Finally, note that in plurality voting with a runoff there is a wasted vote problem in the sense that voters may not want to vote according to their true preferences in the first round for fear that their first choices have no chance of success. In the two-candidate runoff round, however, no votes will be wasted, so that anyone whose vote was "wasted" in the first ballot will have a chance to exercise a meaningful vote in the runoff ballot. In the Reagan-Carter-Anderson election, if the system had called for plurality voting with a two-person runoff, the Anderson voters could have expressed their true preferences in the first round because these voters would have then expected to make a choice in the runoff (presumably) between the candidates of the two major parties.

172 Cf. M. Dummett, supra note 48 , at $272-73$ (arguing that the allegedly simple STV system is actually quite complicated).

173 Cumulative voting is, of course, quite popular in shareholder voting precisely because it enables minorities to gain representation on boards of directors. Similarly, this idea of minority representation is the driving force in proportional representation. Given a situation where $10 \%$ of the voters in every voting district support a minor political party, that party is very unlikely to have any representation in the national assembly if the system requires candidates either to win an absolute majority in some geographical jurisdiction or to defeat all alternatives in head-to-head comparisons. It is more likely, though by no means assured, that these minorities will win some representation if candidates can win elections by some sort of relative majority. In this way, what is regarded by some observers as the weakness of plurality voting may be seen by others as its greatest advantage. See generally $M$. Dummett, supra note 48, at 255-65 ("The electoral system at present in use in Britain and the United States is notoriously ineffective at affording minorities a chance to secure the election of those who will represent their interests."); G. Hallett \& C. Hoag, Proportional Representation (1926) (arguing that fair minority representation is impossible in majority elections).

174 The ideal situation for an extremist hoping for control, not merely representation, is plurality voting with several mainstream candidates. Imagine a situation with six candidates, $A, B, C, D, E$, and the extremist $Z$, where $Z$ is supported by $20 \%$ of the voters but the other $80 \%$ would prefer any of the other candidates to $Z$. If the five mainstream eandidates split the remaining $80 \%$ evenly (each wins $16 \%$ of the total vote), then the extremist will win under simple plurality voting, although $Z$ has no chance under any other system of voting.

This is obviously not an attempt to do justice to the intriguing and difficult question of the ideal form of minority representation in the democratic process. I mean, with these sentences in the text, only to emphasize that the selection of a decisionmaking process in general elections may serve different goals than in deliberative assemblies and other settings. 
competing, features in an election process. There is extensive literature on the theory and implementation of the various plurality systems and, therefore, no reason to review here the popularity of different systems in different parts of the world. It is sufficient to note that variety occurs just where reasonable people can disagree about how to weight different variables and to stress that there are several explanations for the development of this variety outside, but not inside, deliberative assemblies.

\section{Extemporaneous Voting}

It is striking that when ad hoc groups take nonbinding polls or agree to binding votes they do not use round-robin, succession, or motion-and-amendment voting. There is, therefore, less variety than one might expect; moreover, Condorcet alternatives may easily be missed by any process other than round-robin or motion-and-amendment. The groups that $I$ have in mind include sets of friends deciding on the evening's entertainment, a graduating class choosing its commencement speaker, a professor trying to establish the preferences within a class for a review session, and so forth. In these settings, the group uses a decisionmaking procedure, but none has been imposed by external or preexisting rules. ${ }^{175}$

Ad hoc groups most often use a combination of plurality and preference voting. An instructor seeking agreement on a date for a class

175 Juries might be included in this discussion of extemporaneous voting because jurors may sometimes agree, or act as if they agree, to report according to an external rule, such as unanimity for a criminal conviction, but to decide matters internally according to a different rule. See R. Hastie, S. Penrod \& N. Pennington, Inside the Jury 160 (1983) (describing internal voting procedures of a mock jury); see also D. Black, supra note 4I, at 188 (quoting a 1907 article by Francis Galton where the normative value of the median juror's opinion is stressed).

I have, however, excluded jury decisionmaking because the scheme used inside a given jury probably has at least as much to do with the psychology of holdouts and defectors than with group decisionmaking. Imagine, for instance, that a jury told to reach a unanimous decision has been torn among three alternatives and then unanimously agreed to be bound by a plurality vote with a runoff between the two leading alternatives. One would probably not be inclined to puzzle over the use of a rnnoff in this particular setting (as opposed to general elections, town meetings, or classroom settings), because it is easy to imagine that a final vote with more than half the members in favor of one alternative was an important component in securing unanimous agreement among the jurors to abide by the nonunanimous decision. In short, the procedures used in the shadow of formal unanimity or other externally imposed requirements may be strongly influenced by the cast of that shadow and not fairly compared to procedures used elsewhere. 
outing or extra meeting is likely to offer several alternatives, call for a show of hands on these alternatives, and listen for strong minority objection to any one. The plurality winner emerges unless there are at least a few strong voices against it and no similarly strong objections to the second-place finisher. I suspect that many decisions are made in this manner among friends and business associates. Indeed, even at formal meetings, information about individual preferences may be gathered through discussion and afterwards the plurality winner or, if there is some strong dissent, the second-place finisher is put forward as a motion which is generally understood to reflect the "consensus." Polite colleagues generally murmur their affirmative, even unanimous, support for such motions.

The obvious advantage of this form of decisionmaking is that it suppresses evidence of the voting paradox ${ }^{176}$ the disadvantage is that it may miss a Condorcet choice that might easily be discovered through many other forms of decisionmaking. To the extent that such methods are used among friends, one may hazard the idealistic notion that there are no Condorcet alternatives because friends internalize one another's preferences. If I prefer $A$ to both $B$ and $C$, but I know that your preferences are ranked $C B A$, I will not want $A$ to win because I know it displeases you and you, as my friend, may no longer prefer $C$ because it displeases me. There is room for compromise around $B$, but $B$ is not really a Condorcet winner and in more complex situations such a compromise might not readily emerge. In any event, if missing (technical) Condorcet alternatives is not an important problem among friends, then some form of plurality voting may be especially attractive not only because it avoids exposing cycling preferences but also because it may avoid revealing that the friends' eventual compromise is actually a "Condorcet loser."177

176 See supra note 140 and accompanying text.

177 By a "Condorcet loser" I mean an alternative that loses in head-on comparisons to all other alternatives. If there are three voters trying to decide among three alternatives where the preference orders are 123,213 , and 312 , then 3 is a Condorcet loser because it loses to both 1 and 2 in pairwise comparisons. If the person preferring 3 strongly dislikes 1 and 2 while the other two are less committed to their choices, any procedure, such as a round-robin, which makes it clear that 3 was a loser will make its supporter uncomfortable in accepting a friendly offer to accept proposal 3. In contrast, plurality voting may better allow for graceful compromise because, when three alternatives tie with one vote apiece, it may be easy for two friends who realize the third's relatively intense dislike of alternatives 1 and 2 to say that, since 
The popularity of plurality voting in classrooms and similar situations is further explained by the irregularity with which such groups meet and vote. In normal deliberative assemblies, it will be recalled, the stimulus to change was described as a majority's dissatisfaction when its preference did not emerge from the decisionmaking process, either because of the importance of order in deciding among cycling preferences or because the procedure simply missed a Condorcet winner. This dissatisfaction hypothesis, however, requires time and repeated observations or votes. When a group votes very infrequently there is no opportunity for the evolution of decisionmaking procedures and no reason to expect subtle disadvantages, such as the failure to deliver a Condorcet winner or to suppress evidence of the voting paradox, to overpower simplicity. ${ }^{178}$ Plurality voting is simple because no one needs to take explicit control of the voting order ${ }^{179}$

there is a tie, the group's decision may as well be 3 . The choice of a Condorcet loser is not readily apparent in this scenario.

Note that although there was a Condorcet loser, 3 , and a Condorcet winner, 1 , in the above example, a Condorcet loser can exist without a Condorcet winner. There could be cycling among three alternatives, all of which defeat a fourth. Imagine, for instance, three voters on four alternatives with the following preferences: 4123,2314 , and 3124 . Obviously, 4 is a clear loser to any other alternative, but no Condorcet winner exists beeause of the now familiar cycling among 1, 2, and 3. For a discussion that touches on this, see Kramer, supra note 26, at 271; see also $\mathrm{H}$. Nurmi supra note 45 , at 45 (discussing Condorcet losers and noting that Borda's preferential process guaranteed that a Condorcet loser would never be chosen).

${ }_{178}$ In extemporaneous voting there is also flexibility in deciding the terms of the process. In a classroom situation, for instance, the instructor may or may not call for a runoff procedure if no one alternative attracts an absolute majority. In more formal settings, such procedures could hardly be introduced midstream.

179 Note, however, that order could affect outcomes in some informal plurality votes. Where voters do not know the other voters' preferences, early returns may serve to reveal information, and, therefore, to affect the outcome. Consider a class of 90 students trying to choose among alternatives, $1,2,3$, and 4 . Twenty students rank the alternatives 1234,30 rank them 2143 , and 40 prefer 3142 in that order. Decisionmaking is by plurality vote with each participant entitled to one vote.

If alternative 1 is presented first, the group of 20 students which ranks 1 first might start to raise their hands, see that they have no chance to win (with three alternatives and 70 votes remaining, some other alternative will necessarily get more than 20 votes), and retract their hands, declining to vote for 1 . They would then shift their support to 2 , assuring the adoption of 2 regardless of the remaining order of consideration.

On the other hand, if 2 is voted on first, and 30 hands are raised, the faction favoring 1 might still think that it has a fair chance of success because three alternatives and 60 votes still remain. In fact, 3 will win. The order of consideration may thus affect the outcome in simple, extemporaneous, plurality voting.

It is interesting to note that triple-ballot voting, that is two rounds of plurality voting followed by a runoff if necessary, very occasionally is used in Japan. If no candidate receives 
and because only one round of voting is necessary.

One final disadvantage, or at least complexity, of plurality voting concerns the interaction between this type of decisionmaking and the voting power of the chair where voting is sophisticated. The problem is suppressed in extemporaneous, informal votes, not because the dissatisfaction hypothesis has no chance to work out, but because there is normally no opportunity for coalitions to form and sophisticated voting to take place. Returning to the earliest example of cycling preferences, consider a six-person committee or other group where $A$, the chair, and $B$, a member, rank the alternatives $123, C$ and $D$ rank them 231, and $E$ and $F$ rank them 312. If there is simple plurality voting and $A$ is entitled to a deliberative and a casting vote, there will be two votes for each alternative and $A$ will cast in favor of 1 . If we allow for some sophistication, however, $E$ and $F$ may see this outcome on the horizon and convince $C$ and $D$ to vote for 3 because all four prefer 3 to 1 . If the chair has only a casting vote, however, then a simple first-round vote will produce one vote for 1 and two votes for both 2 and 3 , and $A$ will break the tie by voting for 2 . $B$ may be able to talk $E$ and $F$ into voting for 1 in the first round, but $C$ and $D$, anticipating $B$ 's pitch, may convince $E$ and $F$ that they should all vote for 3 (rather than 1). This last scheme requires some trust, however, because $E$ and $F$ may fear that $C$ and $D$ will in fact vote for 2 inasmuch as they can anticipate that $A$ will break a tie between 2 and 3 in favor of 2 .

The counterintuitive point of this small excursion into coalitions and sophisticated voting is known in the collective choice literature: With sophisticated voting in a plurality format, the chair may have less real power when it is given more apparent power. ${ }^{180}$ The chair's deliberative and casting votes in the previous example led other voters

an absolute majority in the first round, another round of plurality voting is carried out before a runoff is used as a last resort. Among the other features of this decisionmaking strategy, the first round of plurality voting may serve to provide information which facilitates the formation of coalitions. In the above example, supporters of 1 may wish that 1 were not considered first, but in triple-ballot voting, they would probably be quite indifferent about the order of consideration. Legislatures and organizations in Japan generally use more familiar decisionmaking rules. Indeed, the only Japanese work on procedure for (nonlegislative) meetings I have found is an adaptation of Robert's Rules and similar systems. T. Hayakawa, Kaigiho no Joshiki [Rules of Meetings that Everyone Should Know] (1985) (generally using the motion-and-amendment process with simple majority voting).

180 See R. Farquharson, supra note 43, at 63. 
to deny the chair its ability to break ties. Inasmuch as this conclusion depends entirely on the ability of voters to strategically form coalitions, ${ }^{181}$ a possible disadvantage of plurality votimg is the great uncertainty created in choosing the chair's voting power. Put differently, although a group needs to choose among unattractive alternatives in deciding how to empower its chair, the most unattractive alternative may be uncertainty. And plurahity voting generates the most uncertainty about the effect of giving or withholding casting and deliberative votes.

It is no accident, I think, that plurality voting is used precisely where no decision need be made about the chair's voting power. In ad hoc groups, where plurality voting is especially common, and in general elections, where plurality voting is relatively common, there is virtually no possibility of a tie-breaking vote. In general elections the number of voters is so large that a tie is virtually impossible, and in ad hoc groups, such as classrooms and sets of friends, there is simply no chair whose casting vote might stimulate an earlier bargain. ${ }^{182}$

In sum, plurality voting in "extemporaneous" decisionmaking can be understood by noting that: Plurality voting suppresses evidence of uncomfortable cycling preferences and is simple enough to avoid the need for an authority to set the agenda or voting order; such votes often involve friends whose interactive preferences make Condorcet choices unlikely; in occasional settings dissatisfaction has insufficient opportunity to materialize and influence the development of decisionmaking processes; and the absence of a chair in these and other circumstances where plurality voting is common avoids the confusion and dissatisfaction which may otherwise arise in deciding what voting power to grant the chair.

\section{CONCLUSION}

The rnles by which groups reach decisions form one of the purest examples of customary law. Legislatures vote to be governed by specific rules of procedure, to be sure, but by and large thousands or even millions of groups, without the help of legislatures or judges, decide

181 If voters are unable to form coalitions, the extra vote obviously makes the chair more powerful.

182 Even in the typical classroom setting, for instance, the instructor could offer several dates for a review session and really be indifferent among them. 
formally and informally how to reach decisions. Constraints are rarely imposed on these groups by virtue of political power. In assessing the development of these decisioninaking procedures it is pointless to ask the usual question of whether the law is efficient or fair. The central message of basic collective choice theory is, after all, that there will be some problem with every decisionmaking process. I have explored, instead, the unifornity and variety of some decisionmaking rules and have sought to make some sense of how people have decided to decide things. The exercise has produced, I think, a strong positive theory which explains a remarkable number of decisionmaking rules. Moreover, unlike most positive theories, this one is accompanied by an evolutionary theory, built around the idea of dissatisfied majority coalitions, which explains how things came to be as they are. I began this project wondering only whether there was anything interesting about Robert's Rules of Order (unaware even that Robert had numerous competitors) and I have been reminded once again of the richness of laws and custoins, the ingenuity of our predecessors, and the depth of the problems with which they grappled. 